\title{
Interdisciplinary Research and Environmental Law
}

\author{
Dave Owen ${ }^{*}$ and Caroline Noblet ${ }^{* *}$
}

This Article considers the involvement of environmental law researchers in interdisciplinary research. Using a survey and a series of unstructured interviews, we explore environmental law professors' level of interest in such research; the extent of their engagement in it; and the inducements and barriers they perceive to such research. We conclude that levels of engagement in such research are probably lower than they ought to be, and we therefore recommend steps that individuals and institutions could take to facilitate more and better interdisciplinary work. More generally, we conclude that some common critiques of interdisciplinary legal research rest on assumptions that are not accurate, at least for the subfield of environmental law.

Introduction 888

I. Background: Why (and Why Not) Interdisciplinary Legal Research?

A. Why Interdisciplinary Research? ............................................ 892

B. Why Not Interdisciplinary Research? ....................................... 895

1. Practical Difficulties............................................................. 895

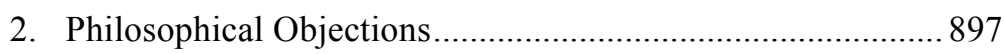

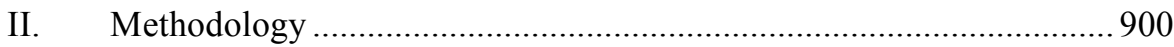

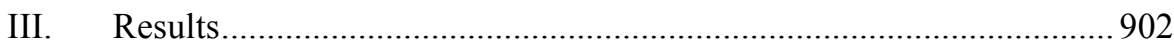

A. Levels of Involvement and Interest ........................................ 902

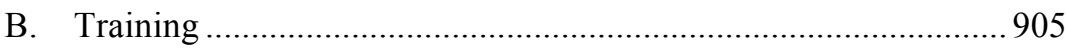

C. Impediments and Inducements to Involvement ........................907

1. Time, Culture, and Learning ................................................ 909

2. The Importance of Contact................................................... 909

3. Publication and Credit........................................................ 911

4. Difference Pre- and Post-Tenure ............................................ 913

IV. The Place of Interdisciplinary Environmental Law Research .............. 916

V. Facilitating Interdisciplinary Legal Research .................................. 918

A. Steps for Law Schools and Universities................................. 919

1. Facilitating Contact ........................................................... 919

2. Crediting Nondisciplinary Publications and Coauthored Works 


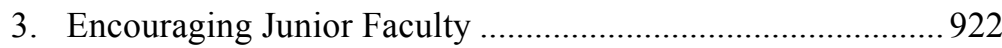

4. Training ....................................................................... 923

B. Steps for Individual Legal Researchers....................................925

C. Steps for Individual Nonlegal Researchers ................................ 926

1. Environmental Law Professors' Interest in Interdisciplinary Work ...................................................... 926

2. Understanding Legal Research Questions ........................... 927

3. Understanding Legal Research Institutions ......................... 929

Conclusion

Appendix A: Survey Questions ................................................................ 932

\section{INTRODUCTION}

In 2011, while speaking at a judicial conference, John Roberts, the Chief Justice of the United States Supreme Court, offered a scathing assessment of the current status of legal scholarship. "Pick up a copy of any law review that you see," the Chief Justice claimed, "and the first article is likely to be . . . the influence of Immanuel Kant on evidentiary approaches in 18th century Bulgaria, ... which I'm sure was of great interest to the academic that wrote it, but isn't of much help to the bar."1

His statement - and, more particularly, its implied disdain for the integration of philosophy and history into legal research - reflects a broader debate. Since the nineteenth century, many prominent legal thinkers have called for the study of law to be more interdisciplinary. ${ }^{2}$ Oliver Wendell Holmes, Jr., for example, famously opined that "for the rational study of the law the blackletter $\operatorname{man}^{3}$ may be the man of the present, but the man of the future is the man of statistics and the master of economics." 4 In the decades since, many law professors have heeded his advice, and legal-academic research now draws upon economics, history, sociology, psychology, and many other nonlegal fields. $^{5}$ That evolution in legal research follows a broader trend toward

Copyright (C) 2014 Regents of the University of California.

* Professor, University of Maine School of Law. The authors thank Karen Bradshaw, Susan Gardner, Karen Hutchins, Sharon Jacobs, Michael Livermore, Bridie McGreavy, Melissa Scanlan, Miriam Seifter, and Jessica Wentz for helpful comments on the survey design and Dmitry Bam, Sarah Schindler, Jennifer Wriggins, participants at the Harvard, Stanford, and Yale Junior Faculty Forum for comments on earlier drafts, and the staff of Ecology Law Quarterly for editorial assistance.

** Assistant Professor, School of Economics, University of Maine.

1. John C. Roberts, Chief Justice, U.S. Supreme Court, Remarks at the Fourth Circuit Appeals Court Annual Conference (June 25, 2011), available at http://www.c-span.org/video/?300203$1 /$ conversation-chief-justice-roberts.

2. For an overview of the history of interdisciplinary legal work, see Jack M. Balkin \& Sanford Levinson, Law and the Humanities: An Uneasy Relationship, 18 YALE J.L. \& HuMAN. 155 (2006).

3. Lawyers use the term "black-letter law" to refer to clear and settled legal rules.

4. Oliver Wendell Holmes, Jr., The Path of the Law, 10 HARV. L. REV. 457, 469 (1897). Holmes remains one of the most revered jurists in United States history.

5. See generally BRIAN Z. TAMANAHA, FAILING LAW SCHOOLS 57 (2012) ("Interdisciplinary and empirical studies of law are especially popular at the moment."); Kathleen M. Sullivan, Foreword: 
interdisciplinary research in industry, government, and academia. ${ }^{6}$ But the trend has long had its detractors, and Justice Roberts's remarks distill their primary objections. ${ }^{7}$ Critics have argued, sometimes rather forcefully, that interdisciplinary legal research is esoteric and impractical, and that its rise is harming traditional doctrinal scholarship and, perhaps, legal teaching. ${ }^{8}$ These perceptions are by no means universally shared, and some of the critics would probably apply their critiques only to some types of interdisciplinary research. ${ }^{9}$ Nevertheless, at an insecure time for the legal academy, even a smattering of barbs can carry a little extra sting. ${ }^{10}$

While these debates have been long-lasting ${ }^{11}$ and sometimes intense, the ample literature on interdisciplinary legal research contains little empirical exploration of what law professors are actually doing. ${ }^{12}$ Many legal authors writing about interdisciplinary legal research assume - usually implicitly — that they know what their colleagues' research practices are, and many articles move rather quickly from summarizing conventional wisdom or snippets of

Interdisciplinarity, 100 MICH. L. REV. 1217 (2002) (discussing the "explosion of perspectives on the law in legal scholarship").

6. See generally COMM. ON FACILITATING INTERDISCIPLINARY RESEARCH, NAT'L ACAD. OF SCIS., NAT'L ACAD. OF ENG'G \& INST. OF MED., FACILITATING INTERDISCIPLINARY RESEARCH (2004) [hereinafter FACILITATING INTERDISCIPLINARY RESEARCH].

7. See, e.g., Brian Tamanaha, Why the Interdisciplinary Movement in Legal Academia Might Be a Bad Idea (For Most Law Schools), BALKINIZATION (Jan. 16, 2008, 9:44 AM), http://balkin.blogspot.com/2008/01/why-interdisciplinary-movement-in-legal.html. But see, e.g., Brian Leiter, More on Interdisciplinary Legal Scholarship and “Non-Elite” Law Schools, BRIAN LEITER's L. SCH. REP. (Jan. 19, 2008), http://leiterlawschool.typepad.com/leiter/2008/01/more-on-interdi.html.

8. See, e.g., Harry T. Edwards, The Growing Disjunction between Legal Education and the Legal Profession, 91 Mich. L. REV. 34 (1992); Brent E. Newton, Preaching What They Don't Practice: Why Law Faculties' Preoccupation with Impractical Scholarship and Devaluation of Practical Competencies Obstruct Reform in the Legal Academy, 62 S.C. L. REV. 105 (2010); Karen Sloan, Empiricism Divides the Academy, NAT'L L.J., Feb. 28, 2011, at 1 (quoting professors concerned that law professors increasingly come from interdisciplinary backgrounds and are weaker legal researchers and teachers); Tamanaha, supra note 7 (questioning whether interdisciplinary research produces any benefits for legal teaching).

9. For a typical counterargument, see Neil H. Buchanan, Why Interdisciplinary Legal Scholarship Is Good for the Law, the Academy, and Society at Large, JUSTIA VERDICT (Jan. 19, 2012), http://verdict.justia.com/2012/01/19/why-interdisciplinary-legal-scholarship-is-good-for-the-law-theacademy-and-society-at-large.

10. See generally TAMANAHA, supra note 5 (criticizing the current legal education system).

11. See, e.g., Robert Kramer, Some Observations on Law and Interdisciplinary Research, 1959 DUKE L.J. 563, 563, available at http://scholarship.law.duke.edu/cgi/viewcontent.cgi? article $=1687 \&$ context $=\mathrm{dlj}$.

12. That is true of the popular press as well as the academic discussions. For example, the New York Times ran a story about the "irrelevance" of legal scholarship. Adam Liptak, When Rendering Decisions, Judges Are Finding Law Reviews Irrelevant, N.Y. TIMES (Mar. 19, 2007), http://www.nytimes.com/2007/03/19/us/19bar.html?_r=0. According to the article:

Articles in law reviews have certainly become more obscure in recent decades. Many law professors seem to think they are under no obligation to say anything useful or to say anything well. They take pride in the theoretical and in working in disciplines other than their own. They seem to think the analysis of actual statutes and court decisions - which is to say the practice of law-is beneath them.

Id. The Times cited no evidence in support of these claims. See id. 
anecdotal evidence to making predictive or normative claims. ${ }^{13}$ That is problematic. According to the American Association of Law Schools, there are over 10,000 law professors in the United States alone, and they are distributed across dozens of subfields. ${ }^{14}$ The legal-academic world therefore is much too large for any professor or judge to presume broad knowledge of its research practices. Yet that presumption seems prevalent, and the consequence is an important debate only partially moored to actual data.

The absence of data poses another problem: it hamstrings researchers who hope to improve interdisciplinary research. As nearly every study of the subject acknowledges, interdisciplinary research is hard work, at least if it is to be done well. ${ }^{15}$ That literature identifies a variety of challenges, each of which suggests a range of possible responses. ${ }^{16}$ But without documentation of the research practices used and the challenges confronted by specific academic fields, it will be harder for institutions and for individual researchers - both within and outside legal academia - to facilitate successful interdisciplinary collaborations. More broadly, if information can improve interdisciplinary research, that should alleviate the concerns of critics who argue that interdisciplinary research is botched so often that it should be done rarely.

This Article supplies some of that missing empirical information and considers its implications. Our focus is environmental law, which is an interesting subfield for several reasons. First, in practice, environmental law is highly interdisciplinary. Environmental lawyers often work closely with environmental scientists, and the field emerged in reaction to the insights - and warnings - of scientific researchers. ${ }^{17}$ One might hypothesize that a similar level of interdisciplinary engagement would be present, and useful, in academia. Second, and in spite of this potential relationship, the ample literature on interdisciplinary legal research says little about environmental law. ${ }^{18}$ Third, a similar gap emerges in the otherwise substantial nonlegal literature on interdisciplinary environmental research. That literature contains many insights about the challenges inherent in collaborations between

13. For an exception to this generalization, see Mark C. Suchman \& Elizabeth Mertz, Toward $a$ New Legal Empiricism: Empirical Legal Studies and New Legal Realism, 6 ANN. REV. L. \& SoC. SCI. 555, 568-71 (2010) (providing empirical evidence on the extent of legal scholars' collaboration with several other academic fields).

14. About AALS, ASS'N AM. L. SCH., http://www.aals.org/about.php (last visited Sept. 11, 2014).

15. See, e.g., Susan K. Gardner, Paradigmatic Differences, Power, and Status: A Qualitative Investigation of Faculty in One Interdisciplinary Research Collaboration on Sustainability Science, 8 SUSTAINABILITY SCI. 241, 243-45 (2013) (summarizing the literature on different disciplinary perspectives).

16. See infra notes $42-60$ and accompanying text.

17. See John McEldowney \& Sharron McEldowney, Science and Environmental Law: Collaboration across the Double Helix, 13 ENVTL. L. REV. 169, 169 (2011) (emphasizing science's often decisive role in environmental law).

18. See, e.g., Balkin \& Levinson, supra note 2; Sullivan, supra note 5 (focusing on political theory, economics, and philosophy). 
biophysical and social scientists, ${ }^{19}$ but it barely mentions the potential role of law. ${ }^{20}$ Those silences leave environmental law researchers who would like to collaborate with other disciplines, and nonlegal environmental researchers who might benefit from working with lawyers, without information that might help them form such collaborations.

To help supply that information, we distributed a survey to current environmental law professors. We asked about their levels of involvement in interdisciplinary work, levels of interest in that work, and the degree to which training, institutional practices, and other factors create barriers to or incentives for interdisciplinary collaboration. We then supplemented the survey with a series of interviews with environmental law professors involved in interdisciplinary research. ${ }^{21}$

Our findings lead to several key conclusions. Initially, they undercut arguments that the legal academy has abandoned its roots. At least within the environmental law subfield, interdisciplinary work remains a relatively minor part of professors' work. ${ }^{22}$ Moreover, those professors are working with researchers in complementary fields, and they are doing so not because they hope to distance themselves from traditional doctrinal work, but instead because they hope to make their work more practical and useful. ${ }^{23}$ This study therefore provides little support for the view that esoteric interdisciplinary work has come to dominate the legal academy. ${ }^{24}$

Consequently, we argue that the most important question is not how to return law professors to traditional work, but instead how to facilitate more and better interdisciplinary collaborations. We close by offering concrete suggestions to that end. ${ }^{25}$ We hope this discussion will be useful for law professors contemplating a move toward interdisciplinary research, nonlegal professors who hope to involve legal researchers in their projects, and law schools and universities hoping to adopt policies that promote successful interdisciplinary collaborations.

This Article proceeds as follows. Part I summarizes existing literature, both legal and nonlegal, on interdisciplinary research, and highlights several of the key benefits and challenges identified by that research. Part II discusses our

19. See, e.g., Dena P. MacMynowski, Pausing at the Brink of Interdisciplinarity: Power and Knowledge at the Meeting of Social and Biophysical Science, 12 ECOLOGY \& SoC'Y 20 (2007), available at http://www.ecologyandsociety.org/vol12/iss1/art20; Eric D. Roy et al., The Elusive Pursuit of Interdisciplinarity at the Human-Environment Interface, 63 BIOSCIENCE 745, 745 (2013).

20. See, e.g., FACILITATING INTERDISCIPLINARY RESEARCH, supra note 6, at 182. The National Academies' study repeatedly mentions environmental research projects but discusses legal research only once. E.g., id. at 53 (discussing a major research project on the impacts of climate change on regional water supplies). The summary mentions many fields that could contribute to the study, but law is not among them. $I d$.

21. Recordings of these interviews are on file with Owen.

22. See infra note 91 and accompanying text.

23. See infra note 88 and accompanying text.

24. See, e.g., Liptak, supra note 12. Our study does not purport to answer questions about whether legal research generally tends to be excessively esoteric.

25. See infra notes 153-207 and accompanying text. 
methodology, and Part III summarizes our results. Part IV considers the implications of those results for the broader debates about the role of interdisciplinarity in legal-academic research. Finally, Part V turns to recommendations, and provides specific steps that environmental law researchers, law schools, universities, and nonlegal environmental researchers can take to facilitate more effective interdisciplinary collaboration.

\section{BACKGROUND: WHY (AND WHY NOT) INTERDISCIPLINARY LEGAL RESEARCH?}

The literature on interdisciplinary research, both legal and nonlegal, is large and growing. This section provides a relatively short overview of that literature, first explaining why calls for interdisciplinary research are so prevalent, and then discussing the common grounds for skepticism.

Before embarking on that analysis, however, we offer a few words to explain what we mean by interdisciplinary research. According to one leading definition,

Interdisciplinary research . . . is a mode of research by teams or individuals that integrates information, data, techniques, tools, perspectives, concepts, and/or theories from two or more disciplines or bodies of specialized knowledge to advance fundamental understanding or to solve problems whose solutions are beyond the scope of a single discipline or area of research practice. ${ }^{26}$

This definition is expansive and somewhat fuzzy, but it still indicates that interdisciplinary legal research will draw substantially on the methodologies and knowledge of other academic disciplines, rather than being grounded solely in textual research of primary and secondary legal sources.

\section{A. Why Interdisciplinary Research?}

"Interdisciplinary research ... can be one of the most productive and inspiring of human pursuits - one that provides a format for conversations and connections that lead to new knowledge." 27 So begins a major recent study from the National Academies. The authors back their claim with numerous examples, from the Manhattan Project to human genome sequencing, in which collaboration among research disciplines enabled discoveries that would have exceeded the reach of any single discipline acting alone. ${ }^{28}$

There are several reasons why interdisciplinary research can offer such benefits. First, researchers within one discipline can gain valuable input data from researchers in other disciplines. ${ }^{29}$ Lawyers, for example, often draw upon

26. FACILITATING INTERDISCIPLINARY RESEARCH, supra note 6, at 2.

27. Id. at 1 .

28. See id. at $17-18$.

29. Balkin \& Levinson, supra note 2, at 164 ("[T]he most familiar modalities of legal reasoning often seem to call upon knowledge that other disciplines might easily provide."). Whether this counts as interdisciplinary research is a subject of discussion. Some reports refer to this sort of process, where 
the work of historians when trying to understand the historical context for statutory or constitutional provisions. ${ }^{30}$ Second, disciplines can go beyond providing specific input data and can also share broader perspectives and bodies of expertise, which can help researchers define research questions or interpret results. An administrative lawyer's understanding of government agencies, for example, may be quite helpful to a social scientist or public health specialist trying to understand the successes or failings of a government service program. Third, disciplines can share modes of inquiry. Again, legal research provides many examples. Quantitative empirical studies of judicial decisions now are a standard mode of legal-academic analysis, but the recent rise of quantitative empirical scholarship has been closely connected to the increasingly interdisciplinary nature of legal research and of law professors' training. ${ }^{31}$

Interdisciplinary research also can help correct the blind spots of individual research disciplines. A discipline is, by definition, a group of people with a common body of knowledge and skills. ${ }^{32}$ Consequently, disciplines coalesce around shared methodologies and common languages, and that commonality almost inevitably reinforces cultural similarities and shared assumptions. ${ }^{33}$ The resulting intradisciplinary unity has many benefits; most importantly, it allows people within the discipline to communicate efficiently and to establish internal standards for quality work. ${ }^{34}$ But unity easily can become intellectual orthodoxy, and sometimes the incursion of ideas or methods from other disciplines provides an important disruptive effect. ${ }^{35}$

Environmental law already exemplifies these dynamics. The field itself has interdisciplinary origins; it arose largely in response to the research and

information passes between disciplines but the process of actually searching for that information does not involve collaboration, as "multi-disciplinary research." See FACILITATING INTERDISCIPLINARY RESEARCH, supra note 6, at 27-28 ("Research is truly interdisciplinary when it is not just pasting two disciplines together to create one product but rather is an integration and synthesis of ideas and methods.").

30. See generally Laura Kalman, Border Patrol: Reflections on the Turn to History in Legal Scholarship, 66 FORDHAM L. REV. 87 (1997) (providing a cautionary analysis of these practices).

31. See Michael Heise, The Past, Present, and Future of Empirical Legal Scholarship: Judicial Decision Making and the New Empiricism, 2002 U. ILL. L. REV. 819, 823-27 (explaining the role of other disciplines in the rise of empirical legal scholarship).

32. See Douglas W. Vick, Interdisciplinarity and the Discipline of Law, 31 J.L. \& SoC'Y 163, 166-68 (2004).

33. See id. at 169 .

34. See Jack M. Balkin, Interdisciplinarity as Colonization, 53 WASH. \& LEE L. REV. 949, 955 (1996); Vick, supra note 32, at 167 ("The stunning advances in knowledge from the Reformation to the present day, particularly in the physical sciences, can be seen as vindication of this system of disciplinary specialization.").

35. See Vick, supra note 32, at 171 (noting that disciplinary boundaries can become "claustrophobic"). For legal scholars, perhaps the most salient recent example of this dynamic involves behavioral economists crashing a law and economics party previously dominated by rational-actor theorists. See Russell B. Korobkin \& Thomas S. Ulen, Law and Behavioral Science: Removing the Rationality Assumption from Law and Economics, 88 CALIF. L. REV. 1051 (2000). 
advocacy of environmental scientists like Rachel Carson and Aldo Leopold. ${ }^{36}$ In practice, environmental lawyers routinely work with scientists, and the evidentiary materials for most environmental cases include documents written by scientists, engineers, and other technical experts. ${ }^{37}$ Environmental law scholars draw on scientific and economic research when making arguments about whether environmental problems merit government intervention and about the appropriate method and intensity of such intervention. ${ }^{38}$ Indeed, both modes of argument are now so prevalent that one might say that they are distinguishing features of the environmental law field, rather than examples of interdisciplinarity. ${ }^{39}$ Other disciplines also have provided environmental law with new conceptual approaches - the influx of complexity theory provides one of many possible examples — and with potential new research methodologies. ${ }^{40}$ And environmental law researchers have much to offer other fields. Many environmental fields, from communications to planning to conservation biology, are concerned not just with understanding existing systems but also with developing effective policy interventions. ${ }^{41}$ Law is not the only available mode of intervention, but it clearly is an extremely important - and frequently used-option. Consequently, environmental lawyers' knowledge of legal systems and institutions can offer value across a broad swath of environmental research fields.

36. See Zygmunt J. B. Plater et Al., Environmental LaW And Policy: NATURe, Law, AND SOCIETY 9-13 (3d ed. 2004); Mary Jane Angelo, Harnessing the Power of Science in Environmental Law: Why We Should, Why We Don't, and How We Can, 86 TEX. L. REV. 1527, 1527 (2008) ("Environmental law was born out of the new scientific understandings of ecology ....").

37. Every case that one of the authors (Owen) worked on as a practicing attorney met this description.

38. See, e.g., Daniel A. Farber, Probabilities Behaving Badly: Complexity Theory and Environmental Uncertainty, 37 U.C. DAVIS L. REV. 145 (2003) (exploring the implications of complexity theory for environmental regulation); Cass R. Sunstein, The Arithmetic of Arsenic, 90 GEO. L.J. 2255 (2002) (discussing the use of cost-benefit analysis in regulatory decision making).

39. Typical environmental and natural resource law courses, for example, now address concepts like externalities, transaction costs, cost-benefit analysis, environmental trading systems, dose-response curves, ecosystem services, and island biogeography, among others. All of these concepts originated in other fields.

40. See, e.g., Farber, supra note 38; J.B. Ruhl, Complexity Theory as a Paradigm for the Dynamical Law-and-Society System: A Wake-Up Call for Legal Reductionism and the Modern Administrative State, 45 DUKE L.J. 849 (1996). For a sample discussion of ways nonlegal research methodologies could improve legal research, see Dave Owen, Mapping, Modeling, and the Fragmentation of Environmental Law, 2013 UTAH L. REV. 219.

41. For example, the Society for Conservation Biology states that it "advances the science and practice of conserving Earth's biological diversity" and that "[c]ollaboration among scientists, managers, and policy-makers is vital to incorporate high-quality science into policies and management decisions affecting biological diversity." What is SCB?, SOC'Y FOR CONSERVATION BIOLOGY, http://www.conbio.org/about-scb/who-we-are (last visited Sept. 11, 2014). 


\section{B. Why Not Interdisciplinary Research?}

Given all these potential benefits, many academics share the National Academies' enthusiasm for interdisciplinary research. ${ }^{42}$ But such research clearly is no panacea, and there are good reasons why researchers might prefer to avoid it. Some are practical; even if someone is inclined to support interdisciplinary research, she might reasonably balk at the challenges associated with carrying out a successful project. Some of the objections are more philosophical, with critics alleging that interdisciplinary research, even if carried out successfully on its own terms, represents a threat to other, more important work.

\section{Practical Difficulties}

Almost every study of the subject notes that interdisciplinary collaboration is often quite difficult. ${ }^{43}$ There are many traditionally identified obstacles.

First, the shared language and culture that facilitate intradisciplinary collaboration are, by definition, absent from interdisciplinary projects. ${ }^{44}$ That absence of commonality creates the possibility for intellectual breakthroughs, but usually only after sustained effort. ${ }^{45}$ Initially, a common experience of many interdisciplinary researchers is misunderstanding and frustration. ${ }^{46}$ Researchers - particularly those who look to other disciplines as sources of information-often want quick answers to plug into their own established methodologies. ${ }^{47}$ They may not realize just how long it takes for another discipline to answer seemingly simple questions, or how nuanced and caveated the answers are likely to be. ${ }^{48}$ And if the questions really are simple, that also can be problematic. Academics do not build their reputations by answering

42. See MacMynowski, supra note 19, at 20 ("Shared zeal for increasing interdisciplinarity, as well as widespread regard of difficulties, is evident throughout the discussions.").

43. See, e.g., Jessica Leigh Thompson, Building Collective Communication Competence in Interdisciplinary Research Teams, 37 J. APPLIED COMM. RES. 278, 278 (2009) ("[Interdisciplinary research] projects can be challenging for academic experts . ...").

44. See FACILITATING INTERDISCIPLINARY RESEARCH, supra note 6, at 65 ("One of the common themes that runs through any discussion of interdisciplinary interactions is the learning of new disciplinary languages and cultures.").

45. See id. at 77 ("For professors who have secured tenure and would like to pursue [interdisciplinary research], a critical step is to immerse themselves in the 'other' field .... That takes substantial time ...."); Roy et al., supra note 19, at 751.

46. See Art Dewulf et al., A Framing Approach to Cross-Disciplinary Research Collaboration: Experiences from a Large-Scale Research Project on Adaptive Water Management, 12 ECOLOGY \& SoC'Y 14 (2007), available at http://www.ecologyandsociety.org/vol12/iss2/art14/ ("Communication and coordination problems, misunderstandings, and mismatched expectations easily arise.”).

47. See Thaddeus R. Miller et al., Epistemological Pluralism: Reorganizing Interdisciplinary Research, 13 ECOLOGY \& SOC'Y 46, 48 (2008) (describing this form of research as "multidisciplinary"); David N. Wear, Challenges to Interdisciplinary Discourse, 2 ECOSYSTEMS 299, 301 (1999) (noting "[t]he tendency to minimize or compress the content of one discipline to amplify the analysis within one's own").

48. For one of the authors, this dynamic recurred repeatedly during the first two years of an interdisciplinary collaboration. 
simple questions, and finding research questions with sufficient breadth and novelty to interest multiple participants, but sufficient focus to be workable, also can be difficult. ${ }^{49}$ Sometimes just developing mutual respect, or even a common language for communication, takes time..$^{50}$

Second, the logistical challenges can be daunting. Most universities are divided into disciplinary units like schools and departments, each with separate budgets, governance structures, physical facilities, and institutional incentives. ${ }^{51}$ Many of those divisions help maintain coherence and coordination within disciplines, but those same systems can prevent a researcher from working with someone from another field. ${ }^{52}$ Sometimes the challenges are as mundane as physical separation. ${ }^{53}$ Sometimes they involve uncertain funding regimes for co-taught courses, cross-registered students, or jointly funded research endeavors. ${ }^{54}$ Tenure and promotion decisions may be dominated by disciplinary traditionalists, some of whom have trouble evaluating or place little value on interdisciplinary work. ${ }^{55}$ Their skepticism can be compounded by academic publication systems. ${ }^{56}$ While some journals emphasize, or even

49. In interviews, several professors emphasized this challenge. Telephone Interview with David Adelman, Harry Reasoner Regents Chair in Law, Univ. of Tex. Sch. of Law (July 1, 2013) (noting that "it takes a while to establish a rapport and ... a common set of objectives for research with people in other disciplines"); Telephone Interview with Holly Doremus, James H. House \& Hiram H. Hurd Professor of Envtl. Regulation, Univ. of Cal., Berkeley Sch. of Law (July 9, 2013) (noting that many researchers - particularly those who aspire to elite status within their discipline - are "more interested in their research interest dominating whatever they do, their individual interest," and that "it's very hard to do collaborative interdisciplinary work without everybody giving up a little something").

50. See Gardner, supra note 15, at 248-50 (describing uncertain and sometimes tense relationships between social and biophysical scientists in a large-scale interdisciplinary project); Thompson, supra note 43, at 278 ("[W] $[\mathrm{W}$ hat is often ... lacking, is effective management of the communication and collaboration processes.").

51. Chris M. Golde \& Hanna Alix Gallagher, The Challenges of Conducting Interdisciplinary Research in Traditional Doctoral Programs, 2 ECOSYSTEMS 281, 282 (1999) (noting the importance of departmental divisions and the resulting "bias toward disciplinary, rather than interdisciplinary, research").

52. See FACILITATING INTERDISCIPLINARY RESEARCH, supra note 6 , at 72 (noting pressures to fulfill the traditional obligations of the home department and to do interdisciplinary research or teaching on the side). Joint appointments are a potential remedy for this problem, but they bring their own challenges. $I d$. at 70 ("[T] hese researchers may find themselves serving two masters and satisfying neither.").

53. See id. at 77 ("Finding appropriate collaborators can be difficult... especially when they work at distant institutions.”), 94 (emphasizing the importance of physical spaces that promote interaction and "breaking bread" together). Geography also can create opportunities. For example, Stephanie Tai noted that her school's location at the center of its campus facilitates interdisciplinary interaction. Telephone Interview with Stephanie Tai, Assoc. Professor of Law, Univ. of Wis. Sch. of Law (June 21, 2013).

54. In the authors' university system, for example, allowing sustainability science Ph.D. students to register in law school courses without paying law school tuition proved to be a bureaucratic nightmare, despite enthusiastic support from both the law school and the Ph.D. program.

55. See FACILITATING INTERDISCIPLINARY RESEARCH, supra note 6, at 73.

56. See id. at 54 ("If a department or institution rewards only work that produces publications for journals in a narrow disciplinary field, academic researchers will respond accordingly."); Telephone Interview with Daniel A. Farber, Sho Sato Professor of Law, Univ. of Cal., Berkeley Sch. of Law (July 17, 2013) (" $[\mathrm{I}] \mathrm{t}$ can be difficult to find research outlets that work for both of you, particularly on [the nonlegal] side."). 
look exclusively for, interdisciplinary work, the academic norm is a journal identified with a particular discipline, and placing an interdisciplinary article can be challenging. ${ }^{57}$ Many of those challenges are likely to be particularly acute for legal-academic researchers. Law schools, with their orientation toward professional training, are quite different from most other university research departments.

Of course, many of these disadvantages presume that the work will be done in teams. Even with interdisciplinary work, that need not be true; some scholars have training or self-taught expertise in multiple disciplines and can work across disciplinary boundaries without help. Indeed, much of the debate about interdisciplinary legal scholarship emphasizes this model, in which a professor with specialized nonlegal training works in some law-and-(fill-in-theblank) field. ${ }^{58}$ The absence of research teammates can remove some of the problems associated with other forms of interdisciplinary research, for the challenges of schedule coordination and physical separation obviously disappear. And if the researcher really does have deep training in both fields, the ability to speak multiple languages and engage multiple bodies of knowledge has already been learned. But dangers nevertheless persist. One of the most valuable benefits of a team project is the ability of individual members to identify and check the disciplinary biases (or just shoddy thinking) of other members. ${ }^{59}$ When one person works alone, by contrast, the potential for shallow inquiries grows. ${ }^{60}$

\section{Philosophical Objections}

A more fundamental challenge comes from the backlashes against interdisciplinary work. Often traditional researchers view interdisciplinary research as a threat to established disciplines. ${ }^{61}$ That threat may simply arise from the opportunity costs of performing interdisciplinary work. Academics have limited time, and working on an interdisciplinary project often means not working on a more traditional within-discipline research effort—or, potentially,

57. See Wear, supra note 47, at 299 ("However strong the logic behind the development of interdisciplinary journals, the challenges to their successful implementation . . . are substantial.").

58. See, e.g., Hanoch Dagan, Law as an Academic Discipline 8 (Jan. 16, 2013) (unpublished manuscript), available at http://papers.ssrn.com/sol3/papers.cfm?abstract_id=2228433 (describing the work of practitioners in "law and" disciplines). By contrast, the literature on nonlegal interdisciplinary research typically focuses on work done by teams.

59. See Vick, supra note 32, at 185 (noting some of the common pitfalls that arise when legal researchers attempt to draw upon the work of other fields without receiving some assistance).

60. See Brian Leiter, Intellectual Voyeurism in Legal Scholarship, 4 YALE J.L. \& HuMAN. 79, 79-80 (1992).

61. See FACILITATING InTERDisciplinARy RESEARCH, supra note 6, at 22 (quoting Irwin Feller, Presentation at the Annual Meeting of the American Academy of Sciences: Whither Interdisciplinarity (In an Era of Strategic Planning)? (Feb. 15, 2004)) (referring to "the many knowledgeable observers who continue to advise 'staying in one's long-cultivated disciplinary garden' as 'the best way to produce the fruits of scientific discovery"'); Vick, supra note 32, at 173 ("[T] he threat interdisciplinarity poses reinforces the tendency of members of a discipline to jealously guard disciplinary boundaries and marginalize those whose work strays outside those boundaries."). 
on teaching a class. But interdisciplinarity also can threaten the traditional values and skills of a discipline, for the other discipline may seek to displace traditions rather than supplement them. The new discipline may arrive, in other words, not as a collaborator but as a conqueror. ${ }^{62}$

The discourse about legal scholarship includes frequent expressions of these fears. Perhaps their most prominent articulation comes from a law review article by Harry Edwards, a highly respected judge on the United States Court of Appeals for the D.C Circuit. ${ }^{63}$ "For some time now," Judge Edwards wrote in 1992, "I have been deeply concerned about the growing disjunction between legal education and the legal profession." 64 Interdisciplinary research, in his view, was a key culprit for this disjunction. "Our law reviews," he wrote, "are now full of mediocre interdisciplinary articles," which Judge Edwards ascribed to "ivory tower dilettantes." 65 That dilettantism came at a direct cost to traditional doctrinal scholarship because, according to Judge Edwards, "The proponents of the various 'law and' movements generally disdain doctrinal analysis." 66 Judge Edwards repeatedly acknowledged that interdisciplinary work did have a place in the legal academy, at least if done well. ${ }^{67}$ But he also warned that interdisciplinary research, as then practiced, was harming traditional legal research and education. ${ }^{68}$

Two decades later, echoes of Judge Edwards's argument continue to reverberate through the legal world. Chief Justice Roberts's quote is just one example. ${ }^{69}$ Recent law review articles offer similar statements, and the discussion on legal blogs has often been even more emphatic. ${ }^{70}$ To some extent, these arguments simply repackage age-old critiques of academia; the notion that scholars tend to pursue impractical and esoteric inquiries is not exactly new, and traditional disciplinary work is by no means immune to those charges. But the arguments against interdisciplinary legal work nevertheless reflect a conviction - not universally held, but still perhaps widely shared - that interdisciplinary research is particularly likely to lead legal academics astray.

62. See Balkin, supra note 34 , at 954 .

63. Edwards, supra note 8.

64. Id. at 34 .

65. Id. at 36 .

66. Id.

67. Id. at 49 ("It is difficult to dispute, I think, that these various nontraditional movements have the potential to be valuable additions to the law school.").

68. See id. at 37-38 ("The 'impractical' scholars, too, often scorn each other, with the adherents of the various interdisciplinary approaches taking the view that all other approaches are deluded. This view, combined with ideological bias, makes for aggressive intolerance.... The atmosphere is ... profoundly inhospitable for law students."), 40 (referring to the "arrogant, antidoctrinal bias of interdisciplinarians"), 48 (arguing that the rise of "law and" scholarship allowed "impractical" scholars to find "a comfortable home in the law school"), 54 ("Clearly multi-disciplinary work is in vogue . ... It may make for more interesting conversation in the faculty lounge, but I'm hard pressed to see that the profession is benefitting." (quoting one of his former clerks, who was then in private practice)).

69. See Roberts, supra note 1 (arguing that legal scholarship is excessively interdisciplinary and esoteric).

70. E.g., Newton, supra note 8; Tamanaha, supra note 7. 
Many of the critiques seem equally concerned with law professors' attitude toward law itself. Critics contend that the focus on interdisciplinarity reflects boredom with or disdain toward traditional legal thinking - and, perhaps, an uneasy sense of inferiority about the status of law schools within university systems. $^{71}$

In some ways, this critique-particularly its association of interdisciplinary research with impractical research-is puzzling. Additional evidence, alternative and (sometimes) more rigorous methodologies, and new bodies of knowledge seem like practical things to introduce into legal research. And a common alternative approach - to search within prior legal doctrine for answers that doctrinal analysis cannot supply-is intellectually sloppy. ${ }^{72}$ Additionally, as some commentators have pointed out, an academic discipline so established, large, and closely tied to a field of professional practice is likely to resist colonization. ${ }^{73}$ But the potential for at least some problems with interdisciplinary research does seem obvious, and that potential, along with the persistence of debate about interdisciplinary scholarship, suggests that several empirical questions are worth exploring.

First, how much interdisciplinary work are law professors actually doing? Justice Roberts's and Judge Edwards's critiques, for example, suggest that interdisciplinary research has become the norm, to the extent that it has largely displaced traditional modes of legal inquiry. Sometimes scholars supportive of interdisciplinary work have said similar things; one recent article, for example, claimed that "[c]ontemporary U.S. law school culture seems to offer two alternatives: adopt an external academic discipline (such as economics, philosophy, history, sociology, or psychology) or relinquish academic or scientific pretensions and delve more deeply into practice professionalism." 74 But claims about the prevalence of interdisciplinary scholarship are rarely coupled with actual data.

Second, who are law professors working with? The standard negative stereotype of an interdisciplinary legal researcher invokes a law-and-politicaltheory professor, for whom reading Foucault in a law school office is just a second-best (but better compensated) alternative to working in the more

71. See Vick, supra note 32, at 186-87 (summarizing critiques).

72. See, e.g., Parents Involved in Cmty. Sch. v. Seattle Sch. Dist. No. 1, 551 U.S. 701, 745-46 (2007). On those pages, the Court emphatically asserted that racial classifications have a demeaning effect, even when those classifications are designed to favor a group that suffered from past discrimination. That is a sociological and psychological claim-in other words, it is not a legal pronouncement, which becomes true by virtue of the Court's authority to proclaim the law-but the Court cited only prior Supreme Court decisions as support. It did not cite - and the prior Court decisions it cited also did not cite - studies from any of the disciplines that might empirically verify or falsify this assertion.

73. See Balkin \& Levinson, supra note 2, at 173-77 (offering reasons, including the need to prepare lawyers for practice, for why the legal academy will resist colonization); Dagan, supra note 58, at 2 ("[L]egal theory compensates" for the limitations of other modes of inquiry "by focusing on the work of society's coercive normative institutions and through its synthetic character.").

74. See Dagan, supra note 58 , at 8 . 
intellectually pure political science or philosophy department. ${ }^{75}$ But are legal researchers really acting as "ivory tower dilettantes," as Judge Edwards described them, pursuing whims with little regard to their societal value or their relationship to those researchers' core competencies, or are they forming collaborations designed to match expertise to problems?

Third, what have the experiences of law professors who have engaged in interdisciplinary research been like? Did they find significant barriers to such work? Did they find it rewarding? Did it help them solve problems, or become better teachers? Do they want to do more? Answering these questions would contribute to a more informed dialogue about the role of the legal academy in disciplinary and interdisciplinary research - and perhaps, to better interdisciplinary work.

\section{Methodology}

To shed light on those questions, we pursued two modes of inquiry. First, we distributed a survey to current environmental law professors at law schools in the United States. ${ }^{76}$ The survey asked questions about the professors' educational backgrounds, their interest and involvement in interdisciplinary work, and the barriers they perceive to pursuing such work. ${ }^{77}$

Second, we conducted interviews. The interview subjects were all law professors, each of whom we thought would have interest in and a distinct perspective on interdisciplinary research. ${ }^{78}$ Most but not all of the subjects had postgraduate, multidisciplinary training. All are involved to at least some extent in interdisciplinary work. While we did repeat some questions, the interviews generally were unstructured, and we tailored our questions to the interests and background of each interview subject.

Our methodology introduces the potential for biases or errors, two of which we think are particularly important. First, it seems quite likely that law professors who are actively engaged in research (not all law professors meet that description) would be more likely than nonresearching professors to

75. See Vick, supra note 32, at 186-87 (noting that citations to Foucault seem to be a pet peeve of the critics of legal interdisciplinarity and describing law's "disciplinary inferiority complex").

76. To select a group of professors to survey, we began with the list of environmental law professors in the American Association of Law Schools's Directory of Law School Teachers. See AM. ASS'N OF LAW SCH., DiRECTORY OF LAW SCHOOL TEACHERS (2012). Because that list is overinclusive, we culled it by removing any professors whose website profiles clearly indicated that they had not engaged in environmental law research in the last five years. If ambiguity remained about whether professors were still engaged in environmental law research, we included them in the survey. In total, 372 professors received the survey and 112 responded. An interesting question, which this study does not answer, is whether a similar study of law professors in another country would produce different results.

77. Appendix A contains the full set of interview questions.

78. We interviewed: David Adelman (University of Texas School of Law); William Boyd (University of Colorado Law School); Alejandro Camacho (University of California, Irvine School of Law); Holly Doremus and Dan Farber (University of California, Berkeley School of Law); Stephanie Tai (University of Wisconsin Law School); Dan Tarlock (IIT Chicago-Kent College of Law); and Michael Wara (Stanford Law School). 
respond to a survey about research. Similarly, law professors who are engaged - or at least interested - in interdisciplinary work are probably more likely to respond to a survey than colleagues who are not interested. We therefore suspect our pool of survey responses may be somewhat biased toward professors with an above-average level of interest and engagement in interdisciplinary research. The same potential bias flows from our selection of interview subjects. We made a choice to focus on people with obvious interdisciplinary experience, and those people are generally likely to have a more positive view of such research than those who have stayed away.

Second, some imprecision unavoidably flows from our use of the phrase "interdisciplinary research."79 The boundaries between academic disciplines, though real, are neither crisp nor static, and determining when research crosses those boundaries is not always a simple matter. ${ }^{80}$ Similarly, complexities arise when one tries to determine how much cross-boundary engagement is necessary for work to qualify as interdisciplinary. Is an environmental law paper interdisciplinary because the author read and cited ecological studies ${ }^{81}$ Or must the author also draw upon research methodologies employed by the other discipline, and if so, to what extent? To put the questions more generally, where on the continuum between traditional doctrinal scholarship and highly integrated interdisciplinary work does one draw the line? ${ }^{82}$ The National Academies' definition of interdisciplinary research, which we used in our survey because it is the closest thing to an industry standard, is so inclusive that it does not really answer those questions. ${ }^{83}$ On some of our survey questions, we partially avoided this conundrum by asking about time spent collaborating with researchers from other disciplines rather than by asking about time spent on interdisciplinary research. ${ }^{84}$ Nevertheless, some questions did use the phrase "interdisciplinary research," and different survey respondents almost certainly construed that phrase in somewhat different ways.

Finally, our methodology cannot fully answer what is probably the most important question about interdisciplinary research. Such research is valuable if

79. See Vick, supra note 32, at 164 ("In practice, the term has been used very loosely by scholars . . . to describe - and justify — a very wide range of academic inquiry, and interdisciplinarity has a tendency to be all things to all people.").

80. For example, drawing clear boundaries between law and political science or between law and history would not be easy.

81. We think the answer is no, but we recognize that some researchers might disagree.

82. Some studies describe "multidisciplinary" research, which draws upon multiple disciplines without really integrating their methodologies, as an intermediate category on this continuum. See Roy et al., supra note 19 , at 745 .

83. See supra text accompanying note 26 (quoting that definition).

84. In some legal-academic fields, where single authors do much of the interdisciplinary work, this question would understate the amount of interdisciplinary work taking place. In environmental law, however, the understatement is likely to be small. Environmental law professors often write articles that draw upon literature from other disciplines and might qualify as interdisciplinary under the most generous meaning of the term. However, single-author environmental law articles that draw upon the methodologies of multiple disciplines rarely appear in legal-academic journals, and environmental law professors typically reach those higher levels of integration by working in teams. 
and only if it produces more insightful and more useful results than the researchers otherwise would achieve, or if it brings insights to new audiences. But evaluating the quality and effects of academic outputs is difficult, particularly if one wishes to focus on recent works whose influence may not yet be apparent. ${ }^{85}$ For purposes of our survey, we did not try to directly answer that question. Our interviews did touch on that issue, as discussed in more detail below, but we do not claim that a small set of interviews can offer definitive answers.

\section{RESULTS}

\section{A. Levels of Involvement and Interest}

Our most important finding is straightforward: environmental law professors are interested in interdisciplinary research. Sixty percent of respondents told us they want to devote more of their time to interdisciplinary work, and not one respondent said that he or she would like to do less. ${ }^{86}$ That same enthusiasm emerged from the interviews. ${ }^{87}$ Indeed, several of the professors we interviewed noted that they had left the sciences and entered the legal field precisely because they thought combining their nonlegal background with legal skills was their best option for effecting social and environmental change. ${ }^{88}$

85. The most common ways to try to assess quality are to perform a detailed review of individual articles or to measure how often articles are cited (either by other academics or in judicial decisions). But the former methodology is much too time-consuming for use in a study of an entire field, and the latter methodology is crude. See David L. Schwartz \& Lee Petherbridge, The Use of Legal Scholarship by the Federal Courts of Appeals: An Empirical Study, 96 CoRNELL L. REV. 1345, 1353-54 (2011) (explaining some of the limitations of judicial citation counts, but also explaining why they remain a useful metric). A judge (or her clerks) may find an article quite useful yet not cite it; an article may be important to legal decision makers other than judges; and academics often cite articles because they provide useful background information or wish to disagree with analysis that the later author believes is misguided.

86. One survey respondent did write the following comment, however:

When I began my teaching career, I was far more enthusiastic about interdisciplinary work than I am now. Identifying research questions that will stimulate and satisfy both my own interests and those of an interdisciplinary research group driven by the need for funding has become more difficult, and I've become less interested in compromising my own interests and values for the sake of a funder's priorities.

87. Telephone Interview with Alejandro Camacho, Professor of Law, Univ. of Cal., Irvine Sch. of Law (June 27, 2013) ("Getting to know other fields can be intellectually satisfying."); Telephone Interview with Daniel A. Farber, supra note 56 ("Today's problems-environmental and energy problems in particular- . . require . . input from multiple disciplines.”); Telephone Interview with A. Dan Tarlock, Distinguished Professor of Law and Dir. of the Program in Envtl. \& Energy Law, IIT Chi.Kent Sch. of Law (July 17, 2013) ("For me, it's been fantastic.”).

88. E.g., Telephone Interview with David Adelman, supra note 49 ("I wanted to do work that had more immediate consequences. ... I had become increasingly interested in environmental issues .... I didn't necessarily feel like I could do what I wanted to . . . just being a scientist.”). Similarly, Michael Wara described how, while finishing his Ph.D., he began talking to people he thought were playing interesting roles in climate policy, and "a lot of them were lawyers." Telephone Interview with Michael 
Consistent with that interest, and with perceived trends described in the general legal-academic literature on interdisciplinary work, environmental law professors appear to be doing more interdisciplinary work. ${ }^{89}$ Fifty percent of professors reported doing increasing amounts of interdisciplinary work over the course of their careers, and 37 percent reported that they were doing about the same amount of interdisciplinary work. Only 10 percent reported doing less.

We also asked who environmental law professors were working with. The answers revealed a wide variety of collaborators spanning thirty-one different fields. ${ }^{90}$

Wara, Assoc. Professor of Law and Justin M. Roach, Jr. Faculty Scholar, Stanford Law Sch. (June 21, 2013).

89. We say "appear to be" because it is possible that these answers indicate that the normal career trajectory of environmental law professors involves increasing amounts of interdisciplinary work, not that the field as a whole is becoming more interdisciplinary. However, we think the latter explanation is more likely. As Dan Tarlock pointed out, collaborative interdisciplinary work was not a major part of environmental research in the early years of the field. See Telephone Interview with A. Dan Tarlock, supra note 87. "You tried to understand the science," he said, "but as a consumer and synthesizer of it .... There's a tradition, at least going back to the thirties, at Yale and Columbia, and other places, of doing empirical research. In environmental law, it didn't quite fit.... I think we were not... particularly interested in what was going on in the field, so to speak, as trying to understand what the scientists were telling us about the various problems." Id.

90. While this point may seem obvious, the answers underscore the importance of subfieldspecific data to any discussion of interdisciplinary legal research. Some prior articles contain broad proclamations about which other fields law professors tend to work with. See, e.g., Balkin \& Levinson, supra note 2, at 181 (asserting that economics and history have proved most useful to legal scholars). Those claims may be true, and economics clearly has been quite important to the subfield of environmental law. But history has not been so centrally important to environmental law researchers, while ecology — which is probably of little use to corporate lawyers or legal theorists - is the leading focus of collaborative efforts. Interestingly, survey recipients reported little collaboration with disciplines traditionally identified as humanities. 
TABLE 1: REPORTED DisCIPLINES OF COLLABORATORS

\begin{tabular}{|l|c|}
\hline Responses & Response Percent (n=93) \\
\hline Ecology & $45.5 \%$ \\
\hline Economics & $39.0 \%$ \\
\hline Political Science & $35.1 \%$ \\
\hline Biology & $33.8 \%$ \\
\hline Geography & $28.6 \%$ \\
\hline Planning & $28.6 \%$ \\
\hline Climatology & $20.8 \%$ \\
\hline Public Health & $16.9 \%$ \\
\hline History & $14.3 \%$ \\
\hline Philosophy & $11.7 \%$ \\
\hline Geology & $7.8 \%$ \\
\hline Engineering & $5.2 \%$ \\
\hline Toxicology & $5.2 \%$ \\
\hline Hydrology & $3.9 \%$ \\
\hline Psychology & $3.9 \%$ \\
\hline Sociology & $3.9 \%$ \\
\hline
\end{tabular}

The evidence of high levels of interest, growing involvement, and connections with many fields might suggest that interdisciplinary research is now a major component of environmental law professors' research activity. Our results show, however, that environmental law professors still spend a relatively small percentage of their research time collaborating with researchers from other disciplines. ${ }^{91}$ Almost three quarters of the respondents reported devoting less than 25 percent of their research activity to such collaborations, and 45 percent of respondents reported doing no collaborative work at all in the last five years. If, as we suspect, our sample of respondents is somewhat biased toward higher levels of interest in interdisciplinary work, these numbers may actually overstate the extent of collaborative interdisciplinary work done by the environmental law field as a whole.

91. We did not ask about the amount of time professors spent on noncollaborative interdisciplinary projects - that is, projects that bridge disciplines but are pursued as solo efforts. Consequently, these numbers will somewhat understate the amount of interdisciplinary work taking place. Nevertheless, we expect the degree of understatement is small. In the experience of one author (Owen), who has read hundreds of environmental law papers in recent years, single-author but interdisciplinary environmental law scholarship exists but is rare. 


\section{B. Training}

We also asked the environmental law professors about prior degrees and research training. These questions served several purposes. First, we hoped to provide information about environmental law professors' qualifications to work in other fields. A common stereotype holds that lawyers are "smart people who do not like math," and one purpose of these questions was to assess the extent to which that stereotype is accurate. ${ }^{92}$ Second, we sought to explore whether law professors' background and training helps predict their level of involvement in interdisciplinary work.

The responses reveal a more complex picture and a much greater diversity of backgrounds than the prevailing stereotype would suggest. A lack of mathematical training clearly limits some legal researchers. Forty-seven percent of respondents lacked formal training in quantitative research methods, and one survey respondent's comment- "I kick myself for not taking stats" captures that conventional view. But 52 percent of the respondents did report formal training in quantitative research methods. Interestingly, a much lower percentage of respondents reported having received formal training in qualitative research methods like surveys or focus groups, and an even lower percentage were trained to use geographic information systems. ${ }^{93}$

\section{TABLE 2: RESPONDENT TRAINING In RESEARCH Methods (N=92)}

\begin{tabular}{|l|c|c|}
\hline \multicolumn{1}{|c|}{$\begin{array}{c}\text { Have you received formal } \\
\text { training in: }\end{array}$} & $\begin{array}{c}\text { Received No } \\
\text { Training }\end{array}$ & $\begin{array}{c}\text { Received Formal } \\
\text { Training }\end{array}$ \\
\hline Quantitative research methods? & $47 \%$ & $52 \%$ \\
\hline Qualitative research methods? & $67 \%$ & $33 \%$ \\
\hline Geographic information systems? & $84 \%$ & $15 \%$ \\
\hline
\end{tabular}

Table 3: Participants' Responses to Percent of Research Time DEVOTED TO INTERDISCIPLINARY RESEARCH ( $\mathrm{N}=94)$

\begin{tabular}{|c|c|}
\hline $\begin{array}{c}\text { Percent of Research Time Devoted to } \\
\text { Interdisciplinary Research }\end{array}$ & Percent of Respondents \\
\hline $0 \%$ & 45 \\
\hline $1-10 \%$ & 28 \\
\hline $11-25 \%$ & 16 \\
\hline $26-50 \%$ & 9 \\
\hline $51-100 \%$ & 2 \\
\hline
\end{tabular}

92. Michael J. Saks, Legal Policy Analysis and Evaluation, 44 AM. PSYCHOLOGIST 1110, 1115 (1989). Of course, one might also conclude that researchers in those fields can offer skills that complement those of legal researchers, at least if they and the legal researchers are able to work around the lack of shared mathematical competency.

93. For this survey, we defined qualitative research methods to exclude traditional legal research based on searching for and analyzing textual sources. 
The survey also revealed a relationship between prior training and present research practices. Not surprisingly, professors with prior degrees in the humanities were more likely, when compared with professors with social or biophysical science backgrounds, to report that they made no use of quantitative methods. ${ }^{94}$ Professors with quantitative training also were more likely to engage in collaborative research. ${ }^{95}$ And in interviews, professors with science backgrounds consistently identified ways in which they thought their background opened research pathways they might not otherwise have chosenor been able - to follow. For some, a key benefit lay in recognizing research questions they otherwise would not have perceived. ${ }^{96}$ For almost all, the specialized training gave them the ability, and credibility, to connect more easily with people outside their field. ${ }^{97}$

\section{Table 4: USE OF QuANTitative Research Methods, BY UNDERGRADUATE MAJOR (N=92)}

\begin{tabular}{|l|c|c|}
\hline $\begin{array}{c}\text { Background } \\
\text { (Undergraduate Major) }\end{array}$ & $\begin{array}{c}\text { Percent of } \\
\text { Respondents }\end{array}$ & $\begin{array}{c}\text { Percent Indicating Zero } \\
\text { Use of Quantitative } \\
\text { Methods }\end{array}$ \\
\hline Social Science & 14 & 31 \\
\hline Bio-Physical & 26 & 28 \\
\hline Humanities & 45 & 51 \\
\hline
\end{tabular}

Nevertheless, prior training was by no means a perfect predictor of present research practices. Fifty-three percent of professors who lacked formal training in quantitative research methods still used those methods, and 78 percent of professors who lacked formal training in qualitative research methods still used those research methods. We did not ask how professors managed to use research methods in which they lacked prior training, and one hypothesis, consistent with some of the critiques of interdisciplinary legal research, is that many law professors are exceeding the limits of their own competence. ${ }^{98}$ But an alternative, and perhaps more plausible, hypothesis is that many

94. Test statistics: $\mathrm{F}=5, \mathrm{P}=.003$.

95. Test statistics: $\chi 2=12.64, \mathrm{P}=.005$.

96. See also Telephone Interview with David Adelman, supra note 49 ("Do I think my background allows me to see problems in different ways, and maybe bring new knowledge and information to bear on important legal questions and or policy issues/questions? Yeah, I think so. I certainly hope so. I'd be depressed if that weren't the case.”); Telephone Interview with Holly Doremus, supra note 49 ("That background has shaped my research agenda in significant ways. It's made questions more appealing to me that I don't think I would have thought about otherwise.").

97. Telephone Interview with William Boyd, Assoc. Professor of Law, Univ. of Colo. Law Sch. (July 16, 2013) (stating that his interdisciplinary background has given him "a broader platform ... for engaging with people across the university and with partner institutions").

98. See Leiter, supra note 60, at 79-80 (warning of the challenges that confront a researcher attempting to work across disciplines). 
environmental law professors are working with research partners who can compensate for the law professors' lack of training. ${ }^{99}$

\section{Impediments and Inducements to Involvement}

Several of our survey questions and many of our interview questions were designed to explore what factors encourage or limit legal researchers' involvement in interdisciplinary work.

Table 5 below summarizes the results of our survey questions about barriers. At first blush, the results seem to suggest that the barriers are relatively modest. That would be a surprising finding, for perhaps the most consistent claim in the ample literature on interdisciplinary collaboration is that it is often very difficult. ${ }^{100}$ Yet for each of the potential barriers we identifiedall based on barriers commonly identified in the existing literature- - minority of respondents agreed or strongly agreed with the survey's statement. ${ }^{101}$ One additional statistic should qualify these results, however: 80 percent of respondents agreed with at least one of the statements below. But even as most respondents agreed that some barriers exist, they did not agree that any one barrier is particularly important. And only 20 percent of respondents strongly agreed with at least one of the statements about barriers.

99. Our collaboration exemplifies this latter approach.

100. See supra notes 43-60 and accompanying text.

101. For a nonlegal study identifying similar barriers, see Roy et al., supra note 19. 


\section{TABLE 5: RESPONDENT PERCEPTIONS OF BARRIERS TO INTERDISCIPLINARY WORK $(\mathrm{N}=92)$}

\begin{tabular}{|l|c|}
\hline \multicolumn{1}{|c|}{ Answer Options } & $\begin{array}{c}\text { Percent of } \\
\text { Respondents Agreeing } \\
\text { or Strongly Agreeing } \\
\text { with Statement }\end{array}$ \\
\hline $\begin{array}{l}\text { The difficulty of identifying collaborators in other } \\
\text { disciplines limits my ability to conduct } \\
\text { interdisciplinary research. }\end{array}$ & 27 \\
\hline $\begin{array}{l}\text { The pressure to publish within my discipline limits } \\
\text { my ability to conduct interdisciplinary research. }\end{array}$ & 41 \\
\hline $\begin{array}{l}\text { The pressure to produce highly placed articles } \\
\text { within my discipline limits my ability to conduct } \\
\text { interdisciplinary research. }\end{array}$ & \\
\hline $\begin{array}{l}\text { The difficulty of scheduling time with potential } \\
\text { collaborators from other disciplines limits my } \\
\text { ability to conduct interdisciplinary research. }\end{array}$ & \\
\hline $\begin{array}{l}\text { My ability to conduct interdisciplinary research is } \\
\text { limited by the challenges I face in understanding } \\
\text { the language, content, or culture of other academic } \\
\text { disciplines (for example, you might want to work } \\
\text { with economists but feel your understanding of } \\
\text { economics is not sufficient to allow useful } \\
\text { collaboration). }\end{array}$ & \\
\hline $\begin{array}{l}\text { My ability to conduct interdisciplinary research is } \\
\text { limited by the challenges other researchers face in } \\
\text { trying to understand the language, content, or } \\
\text { culture of legal research. }\end{array}$ & \\
\hline $\begin{array}{l}\text { The challenge of identifying research questions that } \\
\text { will interest an interdisciplinary research group } \\
\text { limits my ability to conduct interdisciplinary } \\
\text { research. }\end{array}$ & \\
\hline
\end{tabular}

The results of this portion of the survey therefore are mixed. They show that most environmental law professors do perceive barriers to interdisciplinary engagement. Those perceptions may help explain why collaborative interdisciplinary work occupies a relatively small percentage of environmental law professors' research time, even though stated interest is high. But neither survey answers nor interviews allowed us to identify one specific impediment whose importance eclipses all others. Many different barriers and incentives exist, though none are insurmountable. We discuss the key challenges below. 


\section{Time, Culture, and Learning}

Perhaps the most important challenge-and one that intertwines with many others - is the time involved in interdisciplinary collaboration. All interview subjects readily acknowledged that interdisciplinary research "take[s] a long time, and [] still is an ongoing challenge."102 A variety of factors explained the need for time investment, but perhaps the most often-cited was the need to understand the culture and goals of other disciplines. A typical example is Dan Farber's experience with social scientists:

We're talking about a grant proposal and they want to look into things, and I understand what they're saying.... [I]t's not that the issue or the methodology is esoteric, but I don't understand why anyone would want to do that. It takes a while to figure out what makes that an interesting question to them. ${ }^{103}$

Similarly, several interview subjects stressed that people outside the legal academy often misunderstand the kinds of questions that interest law professors. ${ }^{104}$ Ironically, the most commonly cited problem was that nonlawyers tend to ask for help with narrow legal issues - in other words, for the kind of focused legal analyses that critics sometimes allege is the antithesis of interdisciplinary work - rather than on the more systemic questions that tend to interest legal academics. ${ }^{105}$ Dan Tarlock relayed one example that, while somewhat extreme, illustrates the problem. He heard that several scientists at his university were interested in talking about a collaborative project, but then discovered that the scientists really just wanted advice about whether they would risk liability with a research project involving the tagging and releasing of rabid bats. ${ }^{106}$ Needless to say, the answer to that question would not be publishable. Indeed, for a lawyer with any common sense, it would not require any research at all.

\section{The Importance of Contact}

If investing time in learning about other disciplines is an important prerequisite to success, one might expect that spending time interacting with researchers in other disciplines - even in a nonresearch context - would lead to more research collaboration. Our results are consistent with that expectation.

102. Telephone Interview with Alejandro Camacho, supra note 87. Once relationships are established, however, interdisciplinary collaboration can lead to higher numbers of publications. Commenting on an earlier draft of this article, Ian Ayres noted that drafting a data-driven, collaborative law-and-economics paper often requires less of his time than writing a more traditional law review article. None of the environmental law professors we interviewed, however, mentioned that benefit.

103. Telephone Interview with Daniel A. Farber, supra note 56 (emphasis added).

104. See Telephone Interviews with David Adelman, supra note 49, Alejandro Camacho, supra note 87, Holly Doremus, supra note 49, Daniel A. Farber, supra note 56, A. Dan Tarlock, supra note 87.

105. See Telephone Interviews with David Adelman, supra note 49, Alejandro Camacho, supra note 87 .

106. Telephone Interview with A. Dan Tarlock, supra note 87. This episode occurred years ago, before Tarlock was employed at his present institution. 
We found correlations between other forms of interdisciplinary contact and involvement in collaborative interdisciplinary research. Professors who present more often to nonlegal audiences, who hold joint appointments, or who coteach courses with nonlegal professors all are more likely to engage in collaborative interdisciplinary research. ${ }^{107}$ On its own, none of these findings indicates a causal relationship; it is possible that people seek out interdisciplinary training, contact, and research because of an interest in the work of other disciplines, and that the training and other forms of contact did not actually play any causal role in the research. But our interviews - and the existing nonlegal literature on interdisciplinary collaboration-suggest that causal relationships do exist. ${ }^{108}$

The interviews and survey comments also highlighted several ways institutional policies can hinder or promote such nonresearch contact. Stanford Law School, for example, recently switched to a quarter system to align its schedule with the rest of the university system, and thus to allow more crossregistration of students. According to Michael Wara, the change has produced positive results for both pedagogy and research. ${ }^{109}$ Cluster hires, which are designed to create interdisciplinary centers within a university, and interdisciplinary graduate programs can facilitate the same sort of repeated contact. Less ambitiously, interviewees suggested that universities should emphasize interdisciplinary classroom collaboration, reading groups, or social events as mechanisms to help researchers from different fields get to know each other. 110

While we heard examples of universities successfully facilitating interdisciplinary contact, professors also reported circumstances consistent with Dan Farber's observation "that universities do a lot better job talking about interdisciplinary work than actually making it happen." 111 A particularly common challenge is that interdisciplinary engagement, either in the classroom or in research projects, is viewed as a bonus, not as something that can substitute for doing traditional legal research or teaching. In Holly Doremus's words: "Yes, there was support; people were glad of it. But . . . there wasn't a formalized support, there wasn't any expectation that . . . it would substitute for

107. Our statistical results are equivocal on whether attendance at talks by other disciplines correlates with increased engagement in interdisciplinary research. See also FACILITATING INTERDISCIPLINARY RESEARCH, supra note 6, at 94 (discussing the importance of "breaking bread together").

108. See, e.g., Telephone Interview with Holly Doremus, supra note 49 ("Social capital is really important to making interdisciplinary stuff work.").

109. Telephone Interview with Michael Wara, supra note 88 ("That meant that our students could take classes outside of the law school very easily. ... It also means that non-law students are in law school classes with a high rate of frequency. . . I get a third of my students coming from other parts of the university."); see also Telephone Interview with Holly Doremus, supra note 49 ("The other big challenge at Davis was just scheduling, because most of the campus there is on the quarter system and the law school is on the semester system.").

110. E.g., Telephone Interview with Holly Doremus, supra note 49.

111. Telephone Interview with Daniel A. Farber, supra note 56. 
other things." 112 That attitude is not unique to law schools. ${ }^{113}$ In an interview, Alex Camacho reported that his nonlegal collaborators were hearing similar things: "You're doing this work, and that's okay, but ... it's icing on the cake for the work that you're really doing."114

\section{Publication and Credit}

As the preceding comments suggest, issues of publication and credit are intertwined with all of these challenges. The academy often accords lesser status to interdisciplinary research, and that attitude can emerge in several different ways.

One is the challenge of finding a place to publish interdisciplinary work. Most academic journals are oriented toward a particular field, and finding an outlet for work that straddles disciplinary boundaries can be difficult. The peculiarities of the legal-academic publication system exacerbate that challenge. ${ }^{115}$ Almost all legal-academic publications, including the most highly respected journals in the field, are staffed by second- and third-year law students. Article selection decisions therefore are made by students who are just developing expertise in their own field and may lack competence to evaluate interdisciplinary work. ${ }^{116}$ With rare exceptions, the students also make their decisions without peer review. ${ }^{117}$ This system encourages all sorts of strategic behavior, not all of it consistent with producing good scholarship. ${ }^{118}$ As William Boyd put it: "[M]y view is, if you try to get into topics outside of traditional legal fields and seek to make a contribution beyond... legal scholarship, you're likely getting beyond the capabilities and interests of law review editors to really evaluate that work."119 The problem is not unique to legal journals. A complex legal analysis can easily fall outside the competence or interest of editors and peer reviewers at nonlegal journals.

112. Telephone Interview with Holly Doremus, supra note 49; see also Telephone Interview with Alejandro Camacho, supra note 87.

113. See Roy et al., supra note 19 , at 751 .

114. Telephone Interview with Alejandro Camacho, supra note 87.

115. For a detailed discussion of that system and its peculiarities, see Richard A. Wise et al., Do Law Reviews Need Reform? A Survey of Law Professors, Student Editors, Attorneys, and Judges, 59 LOY. L. REV. 1 (2013).

116. To be clear, this statement does not apply to all law students. They bring a diversity of backgrounds to law school, and some have prior training that prepares them for evaluating work that crosses disciplinary boundaries.

117. A few law reviews have introduced limited peer review processes, but the schedule generally is more accelerated than traditional academic peer review. See, e.g., Matt Bodie, Stanford Law Review's Peer Review Process, PRAwfsBlawg (Aug. 16, 2011, 8:44 AM), http://prawfsblawg.blogs.com/ prawfsblawg/2011/08/stanford-law-reviews-peer-review-process.html. Law professors also routinely compensate for the absence of peer review by seeking extensive peer feedback on drafts.

118. The system also creates positive incentives, including an incentive to write in clear, jargonfree prose that a broad audience can read.

119. Telephone Interview with William Boyd, supra note 97. The degree to which this challenge exists may be changing, however. Michael Wara, for example, argued that "law reviews are getting more flexible about what they publish." Telephone Interview with Michael Wara, supra note 88. 
Even if the article does place, challenges of credit remain. While some law schools clearly value articles published outside the law review system, ${ }^{120}$ others do not, ${ }^{121}$ and at many, the status of such publications is ambiguous. ${ }^{122}$ A common legal-academic bias against coauthored works - which are routine in the sciences and an intrinsic part of collaborative research-compounds that problem. ${ }^{123}$ Many of the professors we interviewed thought bias against publications outside a researcher's home discipline is even stronger outside the legal academy. The absence of peer review in most legal-academic publishing is baffling to many nonlawyers, ${ }^{124}$ as summarized by Alex Camacho:

When you tell people that you were publishing a piece in a science journal, there would be some people who would ... treat it like it was a magazine article. And of course the converse would be true ... on an appointments committee for a university-wide interdisciplinary institute with scientists ... a candidate would have listed on their $\mathrm{CV}$ a law review article, and a committee member would say, "Well, that's just a studentedited journal, and you can ignore it." ... They were treating it like it was a school newspaper article. ${ }^{125}$

But these incentives did not all run one way. In interviews and survey comments, many professors emphasized steps their schools or universities had taken to bolster interdisciplinary work. Some of the steps were as simple as

120. See, e.g., Telephone Interviews with Holly Doremus, supra note 49 ("One of the things we do quite well, I think, is evaluate scholarship that appears in other venues than traditional law reviews in a supportive and context-appropriate way. At least, we try very hard to do that, to give people credit for things that they do that appear in other places and to tell them that's a good thing."), Michael Wara, supra note 88 ("I would also say that my colleagues are perfectly comfortable supporting scholarship that is published in other venues so long as it is perceived as of a very high quality.").

121. See, e.g., Survey Comments ("The key issue is that interdisciplinary scholarship is not valued for purposes for promotion and tenure, nor is it particularly well-regarded in the hiring process. Senior faculty are driven by the U.S. News Ranking of the law school sponsoring the journal in which your article appears. Peer-reviewed journals and coauthored work are looked down on."); id. ("I lateraled to another school two years ago. At my first school, the pressure to publish highly-placed single-authored articles severely limited my research. At my new school, that constraint is gone.").

122. See Telephone Interview with Stephanie Tai, supra note 53 ("When you ask them ... if you publish in other journals, will that get counted . . many of them said, no, probably not." (describing her experience with interviews while on the job market)).

123. In an interview, Michael Wara summarized this issue:

In law, you don't tend to make your mentors coauthors, even if someone has really contributed in terms of your thinking and... read through drafts and given you really detailed comments. You wouldn't make that person a coauthor in a law context. In a science context, I think it would be pretty common to do that.

That creates challenges for legal scholars:

You probably can't always be the first author, if you're going to do more than one thing ... and yet, even when you are the first author, sometimes there are questions about ... was this really your idea, particularly if the second author is senior. And that can be tough to manage.

Telephone Interview with Michael Wara, supra note 88.

124. Some law professors also find it baffling. But the law review system does have significant virtues, including shorter time lags from submission to publication, an extraordinary level of sourcechecking (law review editors check the form and accuracy of every footnote in every law review article), and the guarantee that many nonacademic lawyers have some prior exposure to legal scholarship.

125. Telephone Interview with Alejandro Camacho, supra note 87. 
talking repeatedly about the value of nontraditional research. Others were more concrete. For example, many universities have successfully used cluster hiring, where hiring lines share a focus upon an interdisciplinary problem rather than a shared orientation, to build collaboration. ${ }^{126}$ Similarly, several professors mentioned that their universities have treated interdisciplinary engagement as a key positive factor in internal grant competitions, thus putting real money behind their rhetorical support. Those competitions were powerful mechanisms for breaking the ice and bringing law faculty — particularly junior faculty — into collaborative projects. ${ }^{127}$ And perhaps the most important incentive, which has little to do with any university policy, is the natural intellectual curiosity of academics. As several professors noted, many people outside the legal field are fascinated with law, and many legal academics entered the environmental field in large part because of its interdisciplinary nature. ${ }^{128}$ That mutual curiosity can help overcome a variety of cultural differences and institutional challenges.

\section{Difference Pre- and Post-Tenure}

All of the survey results summarized above are for the entire pool of respondents. But we also asked respondents to tell us their tenure status. When we compare the answers of tenured and nontenured faculty, some differences emerge, though there also were significant variations within each pool of respondents. Similarly, in interviews, professors often suggested that the pretenure period involves different incentives and constraints.

First, pretenured professors are more interested in devoting increased time to interdisciplinary research, but are doing less of that research. Using an adjusted mean, ${ }^{129}$ the mean percent of collaborative interdisciplinary research for nontenured professors was 11 percent, while tenured faculty indicated 21 percent of their research involved interdisciplinary work. Whether that difference results from tenure status is hard to say; when we ran regression analyses that controlled for other variables, that particular result did not remain statistically significant, and we suspect that tenure status is just part of a set of related factors. ${ }^{130}$

126. See Telephone Interviews with David Adelman, supra note 49 (describing this approach at the University of Arizona, but also noting that it does not always succeed), Daniel A. Farber, supra note 56 (describing Berkeley's Energy and Resources Group, essentially an interdisciplinary department: "There's just lots of interactions between ... the guy who does ecology and economists and the person who models power systems on a day-to-day basis and that allows them to really kind of build a common vocabulary and a common sort of set of interests."), Stephanie Tai, supra note 53 (describing this approach at Wisconsin).

127. Telephone Interviews with Alejandro Camacho, supra note 87 ("I think I was on eight proposals the first year."), Stephanie Tai, supra note 53 ("It's actually listed as a factor for internal grant competitions. That's how I got involved in a lot of projects here.").

128. See supra note 88 and accompanying text.

129. For this analysis, individuals who did not identify their tenure status as either "tenure track" or "tenured" were removed (eight respondents).

130. We employed multiple regression analyses to examine factors that may positively or negatively impact the amount of time our respondents devoted to interdisciplinary research. 


\section{TABLE 6: ENGAGEMENT AND INTEREST IN INTERDISCIPLINARY WORK, DiVIDED BY TENURE STATUS (N=92)}

\begin{tabular}{|l|c|c|}
\hline \multicolumn{1}{|c|}{ Answer Options } & Tenure-Track & Tenured \\
\hline $\begin{array}{l}\text { Percent indicating that zero percent of their } \\
\text { research is interdisciplinary }\end{array}$ & $53 \%$ & $25 \%$ \\
\hline $\begin{array}{l}\text { Percent indicating they would like to devote } \\
\text { more time to interdisciplinary research" }\end{array}$ & $88 \%$ & $51 \%$ \\
\hline $\begin{array}{l}\text { Percent disagreeing with the statement that } \\
\text { "When making tenure and promotion decisions, } \\
\text { my law school values involvement with } \\
\text { interdisciplinary research." }\end{array}$ & $50 \%$ & $20 \%$ \\
\hline
\end{tabular}

${ }^{*}$ Responses are significantly different at $p<.10$ level

Second, pretenure professors tend to perceive greater and different barriers to interdisciplinary work. Among our survey respondents, tenure-track faculty members generally tend to perceive their institutions as less supportive of interdisciplinary work. They also differ from tenured faculty in their perceptions of publication pressure. Pretenure faculty members are much more likely to identify the pressure to publish within their discipline, and the pressure to publish highly placed articles, as impediments to interdisciplinary research. ${ }^{131}$ Our interviews corroborated these findings. ${ }^{132}$ While the professors we interviewed consistently stated that they would encourage a junior law professor to try interdisciplinary work, that encouragement was usually tempered with cautionary notes. Most emphasized the importance of complementing interdisciplinary projects with a more traditional disciplinary research agenda, ${ }^{133}$ and one professor suggested pursuing other projects before embarking on interdisciplinary work at all. ${ }^{134}$

We consistently found that use of quantitative research methods, presentation to nonlegal audiences, teaching with professors from other disciplines, and years of overall environmental law teaching increased the likelihood that respondents devoted more time to interdisciplinary research. No other variable was consistently significant through our multiple analyses.

131. Some written comments emphasized this point. E.g., Survey Comment ("Having been pretenure my entire career to date, I can say that the pressure to produce individually-authored, 'legal' articles in order to succeed in the tenure process definitely inhibited coauthored interdisciplinary work.").

132. E.g., Telephone Interview with Daniel A. Farber, supra note 56 ("I think one of the things that holds ... junior faculty back are concerns about where it's okay to publish. You know, will work that's not published in law reviews count?").

133. E.g., Telephone Interviews with William Boyd, supra note 97 ("Make sure you are comfortable writing law review articles."), Alejandro Camacho, supra note 87 ("The conservative route would just be to be very discipline-focused.").

134. Telephone Interview with David Adelman, supra note 49 ("It is not something I would personally propose to do right up front."). Adelman did propose, however, that junior faculty members interested in interdisciplinary work should immediately begin building the professional networks that would support later interdisciplinary collaborations. Id. 
TABLE 7: RESPONSES TO QUESTIONS ABOUT BARRIERS, Divided by Tenure Status (Percent Agreeing/Strongly Agreeing WITH STATEMENT) $(\mathrm{N}=92)$

\begin{tabular}{|c|c|c|}
\hline Potential Barriers & Tenure-Track & Tenured \\
\hline $\begin{array}{l}\text { The difficulty of identifying collaborators in } \\
\text { other disciplines limits my ability to conduct } \\
\text { interdisciplinary research. }\end{array}$ & 33 & 28 \\
\hline $\begin{array}{l}\text { The pressure to publish within my discipline } \\
\text { limits my ability to conduct interdisciplinary } \\
\text { research. }\end{array}$ & 67 & 38 \\
\hline $\begin{array}{l}\text { The pressure to produce highly placed } \\
\text { articles within my discipline limits my ability } \\
\text { to conduct interdisciplinary research. }\end{array}$ & 73 & 39 \\
\hline $\begin{array}{l}\text { The difficulty of scheduling time with } \\
\text { potential collaborators from other disciplines } \\
\text { limits my ability to conduct interdisciplinary } \\
\text { research. }\end{array}$ & 34 & 41 \\
\hline $\begin{array}{l}\text { My ability to conduct interdisciplinary } \\
\text { research is limited by the challenges I face in } \\
\text { understanding the language, content, or } \\
\text { culture of other academic disciplines (for } \\
\text { example, you might want to work with } \\
\text { economists but feel your understanding of } \\
\text { economics is not sufficient to allow useful } \\
\text { collaboration). }\end{array}$ & 23 & 30 \\
\hline $\begin{array}{l}\text { My ability to conduct interdisciplinary } \\
\text { research is limited by the challenges other } \\
\text { researchers face in trying to understand the } \\
\text { language, content, or culture of legal } \\
\text { research. }\end{array}$ & 28 & 36 \\
\hline $\begin{array}{l}\text { The challenge of identifying research } \\
\text { questions that will interest an } \\
\text { interdisciplinary research group limits my } \\
\text { ability to conduct interdisciplinary research. }\end{array}$ & 11 & 29 \\
\hline
\end{tabular}

${ }^{*}$ Responses are significantly different at $\mathrm{p}<.10$ level 
Again, readers should be wary of generalizing from these results. In interviews, several professors described ways in which their institutions had been highly supportive of interdisciplinary work during their pretenure period. ${ }^{135}$ There are also reasons, apart from institutional pressure, why one might expect junior faculty to be less engaged in interdisciplinary research. Particularly in a field like law, where most faculty members lack Ph.D.s, junior faculty may still be figuring out the research norms of their own discipline and therefore may not feel quite ready to engage with others. They also may not yet have built a reputation or a professional network, and their relatively lower profile may decrease the likelihood that other academics will contact them about pursuing projects. Nevertheless, these survey results do suggest that junior faculty tend to feel more institutional pressure to conform to traditional disciplinary norms. ${ }^{136}$

\section{THE PLACE OF INTERDISCIPLINARY ENVIRONMENTAL LAW RESEARCH}

This Article began by summarizing a view-perhaps widespread, at least among practicing lawyers and judges - that esoteric interdisciplinary research has taken the legal academy by storm, leading to a degeneration of standards for both legal research and teaching. That is a harsh critique, particularly at a time when a stagnant economy, declining applicant pool, and complaints about the practice-readiness of graduates all have combined to create a sense of crisis at many law schools. ${ }^{137}$

But this study strongly suggests that a key factual premise of that critique is mistaken, at least for the subfield of environmental law. The vast majority of the work done by environmental law professors does not involve multidisciplinary collaborations. ${ }^{138}$ Nor do many environmental law professors pursue single-researcher interdisciplinary studies. ${ }^{139}$ While such scholarship may be prevalent in other legal-academic fields, environmental law articles that fit that description are relatively rare. That does not mean that environmental law scholars are pursuing purely doctrinal scholarship, without even a nod to the insights of other disciplines. Drawing upon, and citing to, studies from

135. See Telephone Interviews with David Adelman, supra note 49 (describing the University of Arizona as "hugely supportive"), William Boyd, supra note 97 (describing strong support from fellow environmental law faculty at Colorado and from his dean), Alejandro Camacho, supra note 87 (describing support at Notre Dame), Stephanie Tai, supra note 53 (describing the concrete measures that Wisconsin uses to encourage interdisciplinary engagement and to reward it in the tenure process), Michael Wara, supra note 88 (describing strong institutional support at Stanford).

136. That issue does not appear to be unique to law. The National Academies study, for example, noted that it is important to "[p]rovide encouragement and rewards to move bright, early-career staff out of too-narrow disciplinary pursuits." FACILITATING INTERDISCIPLINARY RESEARCH, supra note 6, at 55.

137. See Lincoln Caplan, An Existential Crisis for Law Schools, N.Y. TIMES, July 15, 2012, at SR10.

138. See supra note 91 and accompanying text.

139. This assertion is based on one author's (Owen's) experience reading hundreds of environmental law papers and hearing many others presented at conferences in recent years. 
other fields is now a normal and routine part of environmental law articles. ${ }^{140}$ But most of environmental law professors' research falls within the traditional mainstream of legal scholarship.

The culture of the discipline also continues to promote that traditional work. While environmental law professors clearly are enthusiastic about interdisciplinary work, we found little evidence corroborating the view that they are pushed in that direction. Some schools do have mechanisms designed to promote interdisciplinary collaboration, but even the most effective nudges still are rather gentle. ${ }^{141}$ And countervailing institutional pressures amply balance those gentle nudges. ${ }^{142}$ Publication systems, tenure and promotion criteria, and in-school teaching responsibilities all contribute to a widespread sense that the legal academy continues to push participants toward more traditional activities. ${ }^{143}$

Our research also provides evidence — albeit indirect_-against claims that interdisciplinary research tends to be more esoteric than traditional legal research. Most importantly, the professors we interviewed consistently told us they pursued interdisciplinary work because they thought such work would help them solve important real-world problems. ${ }^{144}$ Indeed, not one interview subject or survey respondent expressed disdain for traditional legal scholarship, and multiple professors emphasized some version of the claim that "there is a distinctive discourse in law and it's an important one." 145 While our interview sample is small, the fields that environmental law professors are collaborating with are consistent with the hypothesis that environmental law professors are doing interdisciplinary work to try to solve problems. Working with ecologists - a field with its own well-documented inferiority complex-makes little sense as a step toward academic ego-building, but quite a lot of sense if

140. In this vein, one survey respondent stated: "I take some issue with the overall premise of the survey, i.e., that legal research and research in economics, biology, etc., can be conducted separately. All strong research is interdisciplinary."

141. See supra notes $109-114$ and accompanying text.

142. See supra notes 109-125, 129-134 and accompanying text.

143. See id. But see Dagan, supra note 58, at 8 (arguing that legal-academic culture now pushes researchers away from traditional legal research).

144. See supra note 88 and accompanying text.

145. Telephone Interview with David Adelman, supra note 49; see Telephone Interviews with William Boyd, supra note 97 (noting the importance of "[t]he critical/analytical skills that [law professors] bring to any type of text"), Daniel A. Farber, supra note 56 ("I also think it's important to make sure you're bringing something to the table as a law professor, right, not just working in some other field that you're not fully trained in, really leveraging your legal training as well."), A. Dan Tarlock, supra note 87 (“[J]ust be sure there's an important legal component to whatever you take on."), Michael Wara, supra note 88 ("I personally value the other kinds of scholarship tremendously, and I get a lot out of it."). Holly Doremus noted that many environmental law professors may feel a little bit out of place in the social culture of a law school. Telephone Interview with Holly Doremus, supra note 49 ("[S]ince I started teaching law school, I have never felt completely comfortable in a law school. Again, my anecdotal impression is that a lot of environmental people feel like that. When you go to our meetings we aren't all dressed up in suits and ties."). But that statement is quite different from asserting that traditional legal analysis is somehow inferior to alternative modes of inquiry. 
the goal is to solve environmental problems. ${ }^{146}$ And environmental law and economics are so thoroughly intertwined that partnering with economists makes perfect sense.

These results will not, and should not, end the debate about the merits of interdisciplinary engagement, even in the field of environmental law. The repeated statements about the challenges of interdisciplinary work, both in the literature as a whole and from the people we interviewed, should be reason for pause. People would not say those things if every interdisciplinary project went well, and researchers ought to carefully consider whether and to what extent they will engage in an enterprise that often ends in disappointment. But even with those caveats, our results provide a partial answer to those who argue that esoteric interdisciplinary research has taken the legal academy by storm. If environmental law is at all typical, no such transformation has taken place.

\section{FACILITATING INTERDISCIPLINARY LEGAL RESEARCH}

To some traditionalists, who believe that law professors should devote their research time primarily to analyzing legal texts, our findings should be reassuring. But while we do not question the importance of such work, we also do not think it should be law professors' exclusive or even predominant output. Instead, law schools and universities should be asking how to promote interdisciplinary environmental law research, not how to restrain it. There are several reasons why.

The first, which articles on interdisciplinary research have emphasized for decades, is the potential for interdisciplinary work to produce better studies. ${ }^{147}$ While environmental law contains no shortage of unanswered questions about legal doctrine, researchers have been poring over similar statutes and regulations for decades, and the potential to produce important new insights using the same old research tools is almost certainly diminished. ${ }^{148}$ Engaging with other disciplines offers the possibility of supplementing traditional legal research with new information, methodologies, insights, and perspectives. ${ }^{149}$

The second is the potential for interdisciplinary research to reach new audiences. Implicit in many of the critiques of legal scholarship - particularly those from the bench-is an assumption that utility for judges is the key

146. See, e.g., Charles A. S. Hall, Making Ecology More Relevant and Powerful for Millennium III (2006) (unpublished manuscript), available at http://www.esf.edu/efb/hall/CharlieHall_essay.pdf (describing problems in the field, and asserting that "ecology has failed to become a solid, respected and predictive science").

147. See supra notes $27-35$ and accompanying text.

148. That does not mean the field is completely static. The use of sections of the Clean Air Act to address climate change, for example, represents an important shift. But recent changes in statutory environmental law - particularly at the federal level - have been significantly more minor than those in fields like financial or health regulation.

149. See, e.g., Survey Comment ("I find that my own work gains enormously from the exchange of ideas and perspectives across disciplines."). 
measure of a legal publication's value. ${ }^{150}$ But the project of shaping environmental law is by no means limited to judges, or even to lawyers. From regulatory economists to corporate compliance officers to agency staff biologists, the world of environmental policymaking is filled with nonlawyers who collectively play enormous roles in implementing - and, often, creating environmental law. ${ }^{151}$ If these people have access to interdisciplinary environmental law scholarship-even indirectly, through education at universities where interdisciplinary collaboration is a norm-their understanding of environmental law's institutions and practices ought to improve.

The third, and admittedly less important, reason is that interdisciplinary research can also be more rewarding. While every interviewee we spoke with emphasized the difficulties inherent in pursuing interdisciplinary research projects, they also emphasized the benefits, and one of the most important benefits was the exciting possibility of learning to see the world in a new and different way. ${ }^{152}$

So how, then, should law schools, universities, and individual researchers promote interdisciplinary environmental work? And, relatedly, how should they promote good interdisciplinary work, which will realize more of the potential benefits of collaboration while reducing the fodder for critiques? We suggest several concrete steps.

\section{A. Steps for Law Schools and Universities}

A consistent theme emerging from both the survey and our interviews is that institutional actions and policies matter. While, as Stephanie Tai put it, "[i]t's really popular for schools to say that they're interdisciplinary," their success in backing that claim varies, and concrete actions make a difference. ${ }^{153}$ For that reason, we offer several suggestions - some original to this study, and others widely endorsed in the existing literature-that law schools and universities should consider.

\section{Facilitating Contact}

Perhaps the most important way universities can facilitate interdisciplinary collaboration is by facilitating contact between members of different

150. See, e.g., Adam Liptak, The Lackluster Reviews That Lawyers Love to Hate, N.Y. TIMES, Oct. 21, 2013, at A15.

151. For example, much of the work of translating the Endangered Species Act into a real constraint on a specific project is done by federal agency biologists. See Dave Owen, Critical Habitat and the Challenge of Regulating Small Harms, 64 FLA. L. REV. 141, 151-52, 170-72 (2012).

152. See, e.g., Telephone Interview with Holly Doremus, supra note 49 ("For me, one of the biggest advantages is just that it's fun.").

153. Telephone Interview with Stephanie Tai, supra note 53. 
disciplines. ${ }^{154}$ That may seem obvious, but it is not something universities always do well. ${ }^{155}$

There are several affirmative steps universities can take to achieve this goal. The most significant, at least in terms of financial commitments, involve creating interdisciplinary centers and hiring people for joint appointments. Clearly those actions can make a substantial difference, at least if the appointments go to people who are respected researchers with a talent for facilitating collaboration, and if the university sustains a long-term commitment to supporting those interdisciplinary institutions. ${ }^{156}$ Similarly, grant funding for interdisciplinary projects provides a powerful incentive for coordination, and seems to be a particularly effective way of bringing junior faculty into interdisciplinary work. ${ }^{157} \mathrm{We}$ also heard many suggestions for more modest activities that still could produce meaningful payoffs. Requiring faculty to document their work with other departments on their annual report form sends a subtle but still meaningful message that such work is valued. ${ }^{158}$ Inviting nonlegal faculty to lunchtime research presentations, encouraging reading groups, and coordinating interdisciplinary social events can help create a culture where people from different disciplines routinely talk to each other. ${ }^{159}$ Our interviews, survey results, and the existing nonlegal literature on interdisciplinary collaboration all suggest that such routine contact is an important first step. ${ }^{160}$

Another interesting variation on this theme emerged from our interviews: law schools should think about nonlegal graduate students as vectors for interdisciplinary collaboration. ${ }^{161}$ That obviously creates a challenge for law schools, where almost all enrolled students are pursuing professional rather than research degrees. But there are important steps law schools could take to integrate nonlegal graduate students. Encouraging cross-registration - even if that means adjusting the law school schedule - is an obvious first step (and a

154. See Telephone Interview with Holly Doremus, supra note 49 (emphasizing this point).

155. See Telephone Interview with Daniel A. Farber, supra note 56 (noting this problem).

156. See Telephone Interviews with David Adelman, supra note 49 (describing the success of this approach at the University of Arizona, but also emphasizing the sustained investment it requires), Stephanie Tai, supra note 53 ("I think [cluster hiring] helps a lot too.").

157. Telephone Interviews with Alejandro Camacho, supra note 87, Stephanie Tai, supra note 53. Both Camacho and Tai credited these incentives with jump-starting their engagement in interdisciplinary work.

158. Telephone Interview with Stephanie Tai, supra note 53 (noting that this practice is standard at Wisconsin Law School).

159. See Telephone Interview with Holly Doremus, supra note 49 (suggesting several of these steps); see also supra notes 107-108 and accompanying text (discussing survey results that indicate a relationship between nonresearch contacts and research engagement).

160. See FACILITATING InTERDisCiPLINARY RESEARCH, supra note 6, at 94 (noting that interdisciplinary research functions best as a "contact sport"); see also supra notes 107-114 and accompanying text.

161. See Facilitating InTERDisciplinary Research, supra note 6, at 63-67; Telephone Interview with Daniel A. Farber, supra note 56 ("Graduate students turn out to be really important."). 
step with significant pedagogical benefits). ${ }^{162}$ Similarly, law schools should consider how they will give credit to professors who teach outside the boundaries of the law school, or who serve on Ph.D. committees, rather than viewing such work as a bonus. ${ }^{163}$

\section{Crediting Nondisciplinary Publications and Coauthored Works}

In a survey comment, one professor remarked that "[a]s a junior faculty member, I would feel more secure pursuing interdisciplinary research if my law school explicitly recognized... that publication in [specialized or peerreviewed] journals is as valuable as publication in general law reviews." 164 That comment highlights the importance of one of the simplest steps law schools could take to facilitate interdisciplinary work: recognize the value of publications that do not appear in law reviews, and make that recognition explicit. ${ }^{165}$ Similarly - and perhaps even more importantly - other departments ought to explicitly recognize the potential value of publications in legalacademic journals, even if those journals are not peer-reviewed. The absence of such recognition creates a real and meaningful deterrent to interdisciplinary collaboration. ${ }^{166}$

The functional justification for that step - that it would encourage more collaboration - is backed by some basic common sense. As anyone who reads in multiple disciplines knows, both peer-reviewed journals and non-peerreviewed law reviews contain work that ranges from mediocre to excellent. While one system may be better than the other, each has its merits, ${ }^{167}$ and the differences between individual articles within each system are far greater than

162. See Telephone Interview with Michael Wara, supra note 88 (describing the benefits of schedule coordination at Stanford). Wara also described some of the pedagogical benefits:

I was working on big land use and development projects and . . . to some degree on energyrelated issues, and ... you work in teams. It's not just lawyers. And I think there's a real educational value in developing those kinds of relationships as a professor because then you understand how to bring that kind of approach into the classroom . . . . I think it improved my approach to education to have those kinds of relationships in my work life, and my research life because I bring that approach to the classroom and incorporate some more multidisciplinary approaches in my teaching and I think that helps our students to go out and live in a multidisciplinary world.

Id.

163. See supra notes 120-127 and accompanying text (noting that the absence of credit can be a disincentive to such work). Obviously there are potential issues with allowing law professors to replace law school teaching with teaching outside the law school; most importantly, law school teaching typically is compensated at a higher rate, and the resulting cost differential would need to be absorbed somehow.

164. Survey Comment (brackets in original).

165. See supra notes 120-119 and accompanying text (discussing the importance of this barrier).

166. See Telephone Interviews with Alejandro Camacho, supra note 87, Daniel A. Farber, supra note 56 (noting how bias against law reviews limits nonlegal researchers' engagement with interdisciplinary projects).

167. See Richard A. Posner, Against the Law Reviews, Legal AFF., Nov.-Dec. 2004, at 57. But see Natalie C. Cotton, Comment, The Competence of Students as Editors of Law Reviews: A Response to Judge Posner, 154 U. PA. L. REV. 951 (2006). 
the differences between each system. Judging articles on their individual merits therefore makes much more sense than using the author's choice of publication system as a proxy for quality. ${ }^{168}$

The same general principle should apply to coauthorship: law schools should explicitly acknowledge that coauthored works are potentially as valuable as, or even more valuable than, single-authored works. The absence of such recognition creates a perverse incentive for law professors to avoid interdisciplinary work or, if they are determined to pursue it, to do so on their own, which means squandering many of the benefits of collaboration. That does not mean schools should not ask authors about their relative contribution. Sometimes a coauthor's contribution will be substantial and sometimes it will not, and reviewers for tenure or promotion are entitled to know the difference. But it does mean there should be no presumption against coauthorship, and perhaps even a preference that law professors include some collaborative, coauthored work in their portfolios.

\section{Encouraging Junior Faculty}

Providing express guidance on nondisciplinary publications and on coauthorship would alleviate one of the primary challenges identified by junior faculty. But schools ought to go further. In interviews, we often heard suggestions that junior faculty should approach interdisciplinary work with care, particularly in the first few years of their career. ${ }^{169}$ In part, that advice reflected professors' conviction that developing a strong disciplinary core is a crucial start to an academic career, and an important prerequisite to successful interdisciplinary collaboration. ${ }^{170}$ That conviction makes sense. But the advice also reflected a perception that the legal academy as a whole has rather mixed feelings about interdisciplinary work, and that junior scholars will be safer if their initial efforts are more traditional. ${ }^{171}$

168. There are two other potential arguments for favoring home-discipline journals. One is that such journals are more likely to reach the relevant audience, and the other is that everyone else in the discipline favors such publications, so, like it or not, they define the institution's reputation and prestige. The answer to the former argument essentially echoes the broader justifications for interdisciplinary work: all the arguments that justify interdisciplinary collaboration in the research process also justify interdisciplinary sharing of results. The latter argument, at least as it applies to law school professors, ought to be answered by the practices of elite law schools. If Stanford and Berkeley emphasize giving credit for publications outside law reviews, then such recognition may be a marker of, not a limitation upon, high academic status. See supra note 120 and accompanying text.

169. E.g., Telephone Interview with David Adelman, supra note 49 ("It is not something I would personally propose to do right up front.").

170. E.g., Telephone Interview with Daniel A. Farber, supra note 56 ("I also think it's important to make sure you're bringing something to the table as a law professor, right, not just working in some other field that you're not fully trained in, really leveraging your legal training as well.").

171. E.g., Telephone Interview with Alejandro Camacho, supra note 87 ("The conservative route would just be to be very discipline-focused."). None of the professors we interviewed seemed to share those mixed feelings. They simply thought that a responsible mentor would warn junior faculty that these attitudes remain present in the legal academy and should be accounted for. 
At many schools, that may be very good advice. But we think that the legal academy will be better off if that advice becomes obsolete. The reason is fairly straightforward: doing interdisciplinary work in the formative stages of one's academic career can be a very valuable experience. ${ }^{172} \mathrm{~A}$ basic goal of academic research - including research by pretenure faculty-is to break ground and find new insights, and engaging the perspectives of other disciplines can be a valuable step toward achieving that goal. ${ }^{173}$ Similarly, if a tenure decision in theory is based on a scholar's likely future achievements, then a scholar who has begun building the foundations for interdisciplinary engagement ought to be a stronger prospect than one who has opted for a more limited and safer course. Indeed, an emphasis on disciplinary traditionalism can wind up defining a career-in negative ways. As Holly Doremus put it:

I do think it's a mistake, and I have seen this at various institutions . . . to tell people pretenure: "Don't do that stuff yet. There will be time for that." Because I think that the people who are really motivated by doing interdisciplinary work, they won't be doing the best work that they could if you're telling them to avoid it, and they'll get set in the patterns that they establish, and I don't think it's as easy to change what you're doing posttenure as sometimes is assumed. ${ }^{174}$

That does not mean institutions ought to encourage their junior faculty to engage in interdisciplinary collaborations immediately, without any warnings about the attendant challenges. Doing interdisciplinary work is usually harder than doing traditional disciplinary work, and junior faculty ought to know that. Instead, institutions ought to tell their junior faculty to embrace those challenges, even if that embrace means going through a start-up period with fewer publications, and even if it means risking failure. If the point of the pretenure period is to build a demonstrable foundation for years of academic success, taking those chances should be more valuable, not less, than churning out one additional law review article.

\section{4. $\quad$ Training}

Finally, law schools could provide researchers with better training. Our study demonstrates that law professors with training in nonlegal research methods are more likely to be involved in collaborative research projects. ${ }^{175}$ That is unsurprising; those skills are helpful in such collaborations, and even if the law professors themselves are not actually running the statistical analyses or writing the surveys, their training can at least help them understand what their colleagues are saying and doing. But our survey also revealed that almost half

172. Both authors are relatively junior (Owen received tenure in 2013) and both have had extensive involvement in interdisciplinary research. For Owen, the experience was frustrating at times and extremely valuable on the whole, but that value would not have been realized if Maine Law School had not given him room to risk — and initially find-failure.

173. See supra notes $27-41$ and accompanying text.

174. Telephone Interview with Holly Doremus, supra note 49.

175. See supra notes 94-97 and accompanying text. 
of environmental law professors lack training in quantitative research methods, and two thirds lack training in qualitative research methods. Those results are consistent with one interviewee's assessment of law professors generally: "Many law professors never receive any formal training in methodology or research design." 176

There are several ways in which law schools could address that problem. Emphasizing the hiring of J.D./Ph.D.s, as some law schools increasingly are doing, is one option. ${ }^{177}$ But there are downsides to that approach; most importantly, the time investment necessary to obtain a J.D. and Ph.D. could narrow the pool of candidates for legal-academic positions and discourage aspiring law professors from gaining practice experience. ${ }^{178}$ It also does little to help professors already in the academy. ${ }^{179}$ Consequently, more modest reforms are worth considering. One is to draw upon, and expand, existing training programs for nontraditional legal research methods. ${ }^{180}$ While most of these programs focus on quantitative empirical studies, law schools could create similar programs for other research techniques, and even a research methods speaker series could provide a valuable supplement to traditional legal training. Another possibility would involve the many aspiring professors who use two-year fellowships or visiting professorships as springboards to the entrylevel teaching market. Nearly all of those programs are designed to provide aspiring academics with time to research and write, and many also involve some teaching responsibilities. ${ }^{181}$ But to our knowledge, none includes an instructional component focused on research methods. ${ }^{182}$ That is a missed

176. Telephone Interview with William Boyd, supra note 97.

177. Of course, not all Ph.D.s have relevant research training. Someone with a Ph.D. in English literature may be no more qualified to understand a regression analysis than an average J.D.

178. See TAMANAHA, supra note 5, at 57-58 (describing this trade-off). Some J.D./Ph.D.s avoid the trade-off by delaying their entry into the academy, and thus finding time to pursue a research degree and practice.

179. However, benefits for current professors do exist. Those researchers may serve as resources for colleagues and may help create a culture appreciative of a range of scholarly approaches. See Telephone Interview with Holly Doremus, supra note 49 (stating that at Berkeley Law "there is actually remarkable support for interdisciplinary work ... part of that is because we have the Jurisprudence and Social Policy Program").

180. See, e.g., Training, CENTER FOR EMPIRICAL RES. L., http://cerl.wustl.edu/training/cels14.php (last visited Oct. 27, 2014) (announcing a conference on empirical research methods); 2013 Main Causal Inference Workshop, Nw. L., https://www.law.northwestern.edu/faculty/conferences/ causalinference/frequentist (last visited Sept. 27, 2013).

181. See, e.g., Robin I. Mordfin, The Evolution of the Bigelow Program, REC. OnLINE (June 10, 2014, 8:43 PM), http://www.law.uchicago.edu/alumni/magazine/spring11/bigelow.

182. Owen contacted supervisors or faculty advisors for Harvard Law School's Climenko Program, the University of Chicago's Bigelow Fellowships, and New York University's lawyering program and fellowships, and spoke with recent fellows from several other schools. None of these programs include instruction in research methods. There are reasons for that omission; most importantly, fellows already carry heavy workloads, particularly because many are teaching for the first time. Nevertheless, even a short course in research methods could be a valuable addition as fellows attempt to develop and articulate their future research agenda. And tenured and tenure-track professors might want to sit in as well. 
opportunity, for even a limited and introductory survey of research methodologies and designs could be a valuable addition to those programs.

\section{B. Steps for Individual Legal Researchers}

Even if institutions take all of the above-described steps to facilitate interdisciplinary collaboration, the primary responsibility for initiating such collaborations, and for ensuring their success, will still lie with individual legal researchers. For that reason, we also include some suggestions for law professors - particularly junior ones — who are thinking about including interdisciplinary work in their research portfolios. ${ }^{183}$

The most important suggestion, which emerges from nearly every interview, every article on the subject, and from our own experience, is to expect to invest a lot of time. ${ }^{184}$ Every step of the research process, from identifying collaborators and questions to editing articles, is likely to take longer when researchers work in multidisciplinary teams. Additionally, even prior to embarking on a specific research project, legal researchers may need to invest time getting to know potential collaborators, understanding what researchers from other disciplines are interested in and how they do their work, and exploring possible research directions. ${ }^{185}$ In other words, a lot of reading and talking - and, potentially, a lot of food, walks, or beers - may precede even the initiation of concrete steps toward researching and writing an article. ${ }^{186}$

A closely related suggestion is to invest much of that time in learning about the cultures of other disciplines - and to expect that other researchers will need time and help to understand the culture of legal-academic research. Often researchers approach interdisciplinary projects with an initial excess of optimism; they expect that other disciplines will be able to provide data that can be plugged into traditional disciplinary analyses, and that the communication about methods and goals will come quickly and easily. But almost every discipline's methods are more complex and its insights more nuanced than they initially appear. As a practical matter, that necessitates a fair amount of learning before projects can even get off the ground.

Finally, law professors should consider making short-term sacrifices to facilitate long-term gains. Obviously devoting more time is one potential sacrifice, but it is not the only one. A willingness to work on research issues

183. These suggestions also have implications for law students pursuing research projects. Most importantly, we would caution students who have a few months to pursue a research project against pursuing an interdisciplinary project, unless those students have substantial prior training in the research methods of another field. The timetable for many law students' research projects already is quite compressed, and the additional start-up time necessary to make an interdisciplinary project work could make timely completion impossible. On the other hand, if students do have more time, or do have a relevant background, an interdisciplinary project could be a distinctive and valuable educational experience.

184. E.g., FACILITATING INTERDISCIPLINARY RESEARCH, supra note 6, at 77.

185. See supra notes 48-49, 103-104, 107-108 and accompanying text.

186. See FACILITATING INTERDISCIPLINARY RESEARCH, supra note 6, at 94-95 (discussing the importance of "breaking bread"). 
that fall outside the legal academy's traditional conception of an "interesting" research question is another potentially important step. As several interviewees explained, nonlegal researchers often approach law professors for help with questions that are much narrower than the subjects legal researchers traditionally like to write about. ${ }^{187}$ Sometimes declining such a request will make sense, but an alternative response - to take on the project, even if the research question will not generate an important legal publication-may be an important first step toward building a relationship that becomes a collaborative partnership. ${ }^{188}$ And that partnership may pay dividends in the future.

\section{Steps for Individual Nonlegal Researchers}

So far, our suggestions have focused primarily on the legal academy. But many of the interviewees we spoke with thought that the challenges to interdisciplinary legal research came as much from the nonlegal researchers as from the lawyers. ${ }^{189}$ For that reason, we also include a few suggestions for nonlegal researchers.

\section{Environmental Law Professors' Interest in Interdisciplinary Work}

Perhaps our most important finding - particularly for other academics who are interested in environmental law-is that environmental law professors are generally interested in interdisciplinary work. We found a high level of enthusiasm for such work, as well as widespread interest in doing more of it. ${ }^{190}$ For nonlegal academics who might be interested in working with environmental lawyers, that should be an encouraging finding.

Similarly, nonlawyers should be aware that in some ways, environmental lawyers are likely to be predisposed to interdisciplinary work. Both the practice and teaching of environmental law already are inherently interdisciplinary; for both practicing environmental lawyers and teachers, an ability to draw upon the discoveries of other disciplines is often a professional necessity. ${ }^{191}$ Indeed, many environmental law professors are drawn to the field precisely because it

187. See supra notes $104-106$ and accompanying text.

188. See Telephone Interview with Holly Doremus, supra note 49 ("I think a good way to introduce yourself to people is to make yourself useful to them.").

189. E.g., Telephone Interview with Daniel A. Farber, supra note 56 ("I think law now is much more open to interdisciplinary work than (other) parts of the university ... . We can act as catalysts."). Other researchers, however, noted the enthusiasm of nonlegal researchers for working with lawyers. See Telephone Interview with Michael Wara, supra note 88 ("I think the hard scientists who work on these questions are so excited to work with lawyers and more generally, academics that are familiar, really expert in the policy process .... [They] want to do things that are policy relevant, want to do things that connect what they're doing with kind of the real world and have no idea how to do that.").

190. See supra notes 86-88 and accompanying text.

191. Telephone Interviews with Holly Doremus, supra note 49 ("My anecdotal impression is that environmental law has been more open to interdisciplinary work than . . other areas of law for a while, in part because it's so obvious that our questions ... have the need for what other disciplines can bring."), Michael Wara, supra note 88 (emphasizing the interdisciplinary nature of environmental law practice). 
demands this sort of interdisciplinary engagement. ${ }^{192}$ Consequently, any environmental law professor is likely to have at least some background familiarity with, and interest in, interdisciplinary dialogue. Environmental law professors also are generally trained to write about that dialogue. Written communication about a variety of subjects, many of them nonlegal, is one of the core competencies that law schools attempt to teach, and one of the key bases for law schools' hiring decisions. When the time comes to turn an interdisciplinary collaboration into publications, that skill ought to prove particularly valuable.

Nevertheless, one of the central conclusions of the general literature on interdisciplinary engagement-specifically, that knowing the culture and institutional norms of other disciplines is an important first step-certainly applies to researchers interested in collaborating with environmental lawyers. As Holly Doremus put it, "[A]s in any academic collaboration, you need to think about what the reward system and incentive structure is, so you need a project that's going to interest your legal academic." 193 Particularly with law professors, the culture, reward system, and incentive structure are distinctive in several ways, and we summarize some of the most important ones below.

This discussion comes with an important caveat. As Dan Farber put it, academics "are all different, and law professors are probably a more different group than most people on campus." 194 One statistic in particular captures those differences: our survey recipients reported thirty-one different undergraduate majors. Even on basic philosophical matters-for example, the extent to which they believe in objective, discoverable truth versus the extent to which they view truth as a narrative construct-law school professors tend to hold widely divergent views, and at times the resulting divisions within the legal academy have been bitter and deep. ${ }^{195}$ Anecdotally, environmental law professors seem to be a somewhat more relaxed and collegial group than legal academics as a whole, ${ }^{196}$ but the intellectual diversity within the legal academy means that any generalization about the culture is subject to many exceptions.

\section{Understanding Legal Research Questions}

When we asked law professors what advice they would give to a nonlegal researcher interested in collaborating with environmental law researchers, the answers revolved around a few themes. First, and most consistently, law professors cautioned that nonlawyers should try to understand the kind of research questions that are of interest to law professors. Too often, they agreed,

192. See supra note 88 and accompanying text.

193. Telephone Interview with Holly Doremus, supra note 49.

194. Telephone Interview with Daniel A. Farber, supra note 56.

195. See generally JAMES R. HACKNEY, JR., LEGAL INTELLECTUALS IN CONVERSATION: REFLECTIONS ON THE CONSTRUCTION OF CONTEMPORARY AMERICAN LEGAL THEORY (2012) (chronicling some of the legal academy's intellectual divisions and rivalries).

196. See Telephone Interview with Holly Doremus, supra note 49 ("When you go to our meetings, we aren't all dressed up in suits and ties."). 
nonlawyers ask for narrow additions to basically nonlegal research projects, and those inquiries are unlikely to appeal to a larger legal audience. ${ }^{197}$ That response raises the question, however: what sort of question is of interest to a larger legal audience? To answer that question requires some understanding of both the institutional context and disciplinary culture of legal research.

The most important contextual influence is the publication system for legal-academic work. Law professors publish most of their work in studentedited law reviews, and the most prestigious law reviews are "general interest" journals - that is, journals that publish work across a broad range of legal subjects. ${ }^{198}$ That system creates an incentive for law professors to write on subjects that are likely to interest, or at least be accessible to, second-year law students without specialized training in environmental law. Law reviews' submission systems also create incentives toward writing on broad, generalizable subjects. Law professors use a simultaneous submission system, in which articles are submitted to dozens of law reviews, and in which the odds of an article landing in any particular journal are low, even if the article is quite good. That creates a powerful disincentive toward writing articles that are likely to be of interest primarily within a narrow geographic region, and instead pushes authors to write on subjects that are likely to be of general interest across the country. A final key factor is the traditional length of law review articles. Most legal-academic journals prefer submissions that are between 15,000 and 25,000 words long, which is much longer than a typical article in a science or economics journal. That length allows for more background, and sometimes also more breadth, than is typical in articles published in other academic journals. The upshot of these systems is that environmental law professors are likely to favor more sweeping questions and to be reluctant to tackle questions of narrow, localized interest. ${ }^{199}$

Several other cultural factors bolster the pressures created by the publication system. Like many academic disciplines, law professors tend to be interested in systems. An ecologist might be more interested in questions about how nitrogen or carbon moves through aquatic ecosystems than in discovering the extent to which fish A eats insect B. Similarly, law professors tend to be particularly interested in systemic questions about the allocation of power within our environmental system and about the legal instruments we use to put environmental regulation into effect. ${ }^{200}$ Questions about the appropriate

197. See supra notes 104-106 and accompanying text.

198. Whether these journals should be the most prestigious is a subject of occasional debate.

199. That observation comes with an important exception: if a law professor intends to publish outside of the law review system, the publication pressures change. Nevertheless, the law review system still shapes professors' (and their peers') assumptions about what constitutes quality scholarship.

200. Telephone Interview with Daniel A. Farber, supra note 56. Farber summarized legalacademic culture as follows:

[T] he things that tend to really interest us most are not just things about the nature of the rules, but things that go beyond that into issues of process, institutional design, allocation of authority between different kinds of institutions .... [F] or example, what are problems that are better dealt with through an administrative agency or through litigation, or at the state 
balance of federal and state environmental authority or the judicial role in environmental governance, for example, are therefore likely to be more compelling to an environmental law professor than a question about whether a particular state law will provide adequate protection to some species of fish. ${ }^{201}$ That does not mean that narrow questions are not of interest; many iconic legal publications begin with analysis of a specific case or seemingly narrow controversy. ${ }^{202}$ But generally what makes the analysis iconic is its ability to connect that narrow fact pattern with broader, more generalizable themes.

One last cultural feature distinguishes legal academics, and particularly law professors. They tend to be problem-oriented. ${ }^{203}$ While some law review articles are largely descriptive, a normative claim is an element of most legal scholarship. Often that normative claim takes the form of an argument that legal decision makers-legislators, agency officials, or, particularly often, judges - ought to do something differently. For nonlegal academics who view interdisciplinary engagement as an opportunity to engage the policy world, that feature of legal-academic culture ought to be particularly enticing. But for nonlegal researchers whose projects are likely to be primarily descriptive, it may be a challenge (though not an insurmountable one); most law professors, though certainly not all, are interested in using research to address some practical problem.

\section{Understanding Legal Research Institutions}

In addition to understanding the ways law professors frame research questions, nonlawyers interested in collaborating with law professors ought to know something about the distinctive ways that law professors conduct their research. A few features are particularly relevant.

The first is the role of research assistants (RAs) in legal research. Many law professors use RAs to help conduct research, and some assign their RAs significant roles. But the relationship between a law professor and her RAs is generally quite different from the relationship between a science or economics

level or the federal level, or in legal issues that have, you know, really kind of broad policy implications.

Id.; see also Martha Minow, Archetypal Legal Scholarship: A Field Guide, 63 J. LEGAL EdUC. 65 (2013) (identifying and providing examples of classic approaches to legal scholarship).

201. See Telephone Interview with Daniel A. Farber, supra note 56; E-mail from David Adelman to Dave Owen (Aug. 26, 2013) (on file with Owen) ("Often I find that technical people simply want to know what the relevant law is and how it operates .... Ideally, what you are looking for is a project that raises interesting technical questions, which in turn shed an interesting light on legal doctrines, statutes, or theories.").

202. See, e.g., Robert C. Ellickson, Order Without LAW: How Neighbors SeTtle Disputes (1991) (using cattle management in Shasta County, California to explore the extent to which nonlegal norms can be more influential than law); Joseph L. Sax, Property Rights and the Economy of Nature: Understanding Lucas v. South Carolina Coastal Council, 45 STAN. L. REV. 1433 (1993) (using one Supreme Court decision to explore a clash of worldviews with fundamental implications for environmental policy and law).

203. See Telephone Interview with Holly Doremus, supra note 49 ("[L]egal academics... especially in environmental law ... are more likely to conceptualize themselves as problem solvers."). 
professor and her Ph.D. students or postdocs. For the nonlegal professor, graduate students and postdocs are often true partners in the research. They are likely to play major roles not just in executing the research, but also in designing the project and writing it up. Indeed, a key responsibility of the supervising professor is to help the Ph.D. student or postdoc grow into the role of a lead researcher. The role of a law school RA is typically more limited. ${ }^{204}$ The RA is much less likely to have sophisticated research training, ${ }^{205}$ particularly outside the standard techniques of legal research, and the professor's role, though it usually does include mentorship, generally is not to provide detailed instruction on research methods. Instead, the relationship is typically more transactional, with the professor responsible for the overall project concept, design, and write-up, and the RA handling discrete tasks for a relatively low rate of pay.

The second distinctive feature of legal research is the role of money. Unlike most academics, law professors do not subsist on external research grants. Many receive their research money primarily through internal law school summer funding and therefore rarely go through competitive external grant processes. ${ }^{206}$ The amount of money available to law professors, and those professors' need for that money, also tends to be much smaller than the sums to which nonlegal researchers are accustomed. From an institutional perspective, the most expensive part of legal research is access to searchable databases of legal documents. But for a law professor, that access is free; it comes as a collateral benefit of employment and to law students with their enrollment. That funding system has two significant implications for nonlegal professors who are considering collaborating with law professors. The first is that adding a legal component to the research may cost very little. But the second is that if involving a law professor will require additional funding, the law professor (and her school) may not have much experience with external research grant applications and therefore may not have any idea how to go about seeking that money. ${ }^{207}$

204. See Telephone Interview with Alejandro Camacho, supra note 87 (stressing these differences).

205. There are exceptions. Some law students have prior advanced degrees or are pursuing second careers, or both, and therefore come to law school with sophisticated research skills.

206. One survey response captures this culture: "Money is the biggest barrier. We also do not have a culture in my law school that facilitates grant seeking."

207. See Telephone Interview with Alejandro Camacho, supra note 87 (noting that Notre Dame School of Law, where he began his career and found a generally supportive environment for interdisciplinary work, "was very unfamiliar with structuring of those sorts of things... [and] didn't have any of the infrastructure"). 


\section{CONCLUSION}

To some critics of the legal academy, the subject matter of this Article might seem ironic. If interdisciplinary legal scholarship offers little as research and even less to the process of teaching-if, as one prominent skeptic charges, "no convincing evidence has been provided to demonstrate that 'interdisciplinary studies' will help one whit in the training or performance of lawyers"- then a research project focused on interdisciplinary research practices would seem to be esotericism squared. ${ }^{208}$

But that characterization misses much. The potential research benefits of interdisciplinary work have been thoroughly documented, and there are pedagogical payoffs as well. Environmental lawyers, like lawyers in many other subfields, do not work alone. Instead, their daily business requires interaction with scientists, economists, engineers, and policy specialists, or at least with the written output of those and other disciplines. In most practice areas, an environmental lawyer therefore cannot successfully function without first learning something about those other fields. The law school classroom is a good place to begin that learning, and professors will be much better situated to help if interaction with other disciplines is part of their professional lives.

As this Article documents, succeeding in those interactions is not easy, and the risk of failure with an interdisciplinary project will generally be higher than with a traditional legal research project. Similarly, if legal researchers do not invest enough time in understanding the disciplines upon which they would draw, or with which they would collaborate, the results are likely to be superficial. But if interdisciplinary research is done well, it can generate important new insights, and those insights can affect law, policy, and even teaching, sometimes in ways that directly improve lawyers' performance. We hope this Article will help facilitate those improvements.

208. See Tamanaha, supra note 7. 


\section{APPENDIX A: SURVEY QUESTIONS}

Because the survey was distributed through SurveyMonkey, the formatting that appears below is different from what appeared on the screen. The text is the same.

1. I understand the above description of the research and the risks and benefits associated with my participation as a research subject. I understand that by proceeding with this survey I agree to take part in this research and do so voluntarily.

_ Yes, I would like to continue with the survey.

_ No, I prefer not to participate in the survey.

For purposes of this survey, interdisciplinary research means "a mode of research by teams or individuals that integrates information, data, techniques, tools, perspectives, or concepts from two or more disciplines or bodies of specialized knowledge to advance fundamental understanding or to solve problems whose solutions are beyond the scope of a single discipline or field of research practice." (National Academy of Sciences et al. 2005).

2. Have you conducted environmental law research in the past five years?

Yes the survey).

No (if you answer no, you will not be asked the remaining questions in

3. In the past five years, what percentage of your research projects have involved using quantitative research methods?

$$
\begin{aligned}
& 0 \% \\
& -1-10 \% \\
& -11-25 \% \\
& -26-50 \% \\
& -51-100 \%
\end{aligned}
$$

For purposes of this survey, a "research project" means any major research effort, including projects that lead to books or book chapters, articles, policy briefing papers, or other comparable outputs.

For purposes of this survey, quantitative research methods mean research that relies on statistical, mathematical, or computational techniques. 
4. In the past five years, what percentage of your research projects have involved using qualitative research methods?

$$
\begin{array}{ll} 
& 0 \% \\
- & 1-10 \% \\
- & 11-25 \% \\
- & 26-50 \% \\
- & 51-100 \%
\end{array}
$$

For purposes of this survey, qualitative research methods mean techniques like interviews, focus groups, or participant observations. Qualitative research methods do not include the kinds of textual analysis that form the traditional core of legal research.

5. In the past five years, what percentage of your research activity involved collaborating with researchers from other disciplines?

$$
\begin{aligned}
& 0 \% \\
& -1-10 \% \\
& -11-25 \% \\
& -26-50 \% \\
& -51-100 \%
\end{aligned}
$$

For purposes of this survey, "collaborating" means performing sustained work on a joint research project. Without more, discussing a project with a researcher from another field or obtaining comments on a draft would not qualify as collaborating.

6. Over the course of your career as a law professor, has the amount of time you've spent on interdisciplinary research

Increased

Decreased

- Stayed about the same

_ Not applicable.

7. If you have worked with researchers from other disciplines, what is the primary research discipline of the researchers you work with? Please choose all that apply.

Biology
_Ecology
_Economics
_Geology
_History


Philosophy

Planning

Political Science

Public Health

Climatology

Toxicology

Not applicable

_ Other (please list)

8. In the future I would like to devote:

more of my research time to interdisciplinary research;

the same amount of my research time to interdisciplinary research;

_ less of my research time to interdisciplinary research.

9. In the past five years, what percentage of your research presentations has been to non - legal or mixed audiences?

$$
\begin{aligned}
& 0 \% \\
& -1-10 \% \\
& -11-25 \% \\
& -26-50 \% \\
& -51-100 \%
\end{aligned}
$$

For purposes of this question, a "non-legal or mixed audience" is an audience that contains a substantial number of people whose primary expertise is in a subject other than law. An audience composed partly of lawyers and partly of scientists therefore would qualify as a mixed audience.

10. Please indicate your level of agreement with the following statements.

(a) The difficulty of identifying collaborators in other disciplines limits my ability to conduct interdisciplinary research. strongly agree strongly disagree _ disagree _ neither agree nor disagree _ agree

(b) The pressure to publish within my discipline limits my ability to conduct interdisciplinary research. strongly agree strongly disagree _ disagree _ neither agree nor disagree _ agree

(c) The pressure to produce highly-placed articles within my discipline limits my ability to conduct interdisciplinary research. strongly agree strongly disagree disagree neither agree nor disagree agree 
(d) The difficulty of scheduling time with potential collaborators from other disciplines limits my ability to conduct interdisciplinary research. strongly agree strongly disagree disagree neither agree nor disagree agree

(e) My ability to conduct interdisciplinary research is limited by the challenges I face in understanding the language, content, or culture of other academic disciplines (for example, you might want to work with economists but feel your understanding of economics is not sufficient to allow useful collaboration). strongly agree

strongly disagree _ disagree _ neither agree nor disagree _ agree

(f) My ability to conduct interdisciplinary research is limited by the challenges other researchers face in trying to understand the language, content, or culture of legal research. strongly agree

(g) The challenge of identifying research questions that will interest an interdisciplinary research group limits my ability to conduct interdisciplinary research. strongly agree strongly disagree _ disagree _ neither agree nor disagree _ agree _

(h) other (please specify)

11. Over the past five years have you jointly taught courses with professors from other disciplines?

$$
-\stackrel{\text { No }}{\text { Yes }}
$$

If so, what courses?

12. Over the past five years, approximately what percentage of the academic presentations (lunchtime research presentations, other lectures, and presentations at conferences) you attended were delivered by non -lawyers?

$$
\begin{aligned}
& -0 \% \\
& -1-10 \% \\
& -11-25 \% \\
& -26-50 \% \\
& -51-100 \%
\end{aligned}
$$


13. Does your law school provide financial incentives for engaging in interdisciplinary research?

No
- Yes
- I do not know

14. Please indicate your level of agreement with the following statement:

When making tenure and promotion decisions, my law school values involvement with interdisciplinary research: strongly agree

strongly disagree disagree neither agree nor disagree agree

15. My law school is

_ Public

- Private

16. Is your law school located on the campus of a research university?

No
- Yes

17. For how many years have you been teaching environmental law?

18. Are you...

_tenured

_ tenure-track

_ emeritus

other

19. Do you have a joint appointment within another school or program at your university?

- No
- Yes
If so, which one?

20. What was your undergraduate major? 
21. Do have a postgraduate degree other than a JD?

No
- Yes

If so, what was that degree/were those degrees and what was the subject?

22. Have you received formal training in...

quantitative research methods? _ no__ yes _ N/A

qualitative research methods? _ no__ yes _ N/A

geographic information systems? _ no_ yes _ N/A

For purposes of this survey, please use the following definitions:

Formal training means taking academic courses, participating in training seminars, or receiving other equivalent forms of instruction.

Qualitative research methods mean techniques like interviews, focus groups, or participant observations. Qualitative research methods do not include the kinds of textual analysis that form the traditional core of legal research.

Quantitative research methods mean research that relies on statistical, mathematical, or computational techniques.

23. Are there specific steps you would like your law school to take to facilitate interdisciplinary work?

24. Are there specific steps you would like your university to take to facilitate interdisciplinary work?

25. If you would like to provide additional information in response to any of the questions above, or would like to add anything about your experience with interdisciplinary teaching or research, please do so below.

Thank you for taking the time to complete this survey. 
If you would be interested in providing additional information about your experiences with interdisciplinary research, please contact Dave Owen at dave.owen@maine.edu.

We welcome responses to this Article. If you are interested in submitting a response for our online companion journal, Ecology Law Currents, please contact ecologylawcurrents@boalt.org. Responses to articles may be viewed at our website, http://www.boalt.org/elq. 